\title{
Punished banks' acquisitions: Evidence from the U.S. banking industry
}

\author{
Panagiota Papadimitri $^{1}$, Panagiotis Staikouras ${ }^{2,3}$, Nickolaos G. Travlos ${ }^{4,5}$, Chris Tsoumas ${ }^{6}$ \\ ${ }^{1}$ Portsmouth Business School, University of Portsmouth, UK \\ ${ }^{2}$ University of Piraeus, Greece \\ ${ }^{3}$ Research Fellow, Institute of Global Law, Economics and Finance, QMUL \\ ${ }^{4}$ Surrey Business School, University of Surrey, UK \\ ${ }^{5}$ ALBA Graduate Business School at the American College of Greece \\ ${ }^{6}$ Hellenic Open University, Greece
}

\begin{abstract}
We study whether formal enforcement actions, imposed on U.S. banks during 2000-2014 for serious financial safety and internal control problems, affect the probability that punished banks become targets of mergers and acquisitions (M\&As). We find an increase in the probability of punished banks' acquisitions of at least $0.7 \%$. A similar pattern is identified during both the financial crisis period of 2008-2009 and beyond the 2008-2009 period. Furthermore, these acquisitions improve the operating performance of post-acquisition combined entity, lending support to the hypothesis that punished banks' M\&As serve as a means to replace inefficient management and restore the target banks' performance.
\end{abstract}

Keywords: bank mergers and acquisitions; enforcement actions; inefficient management JEL classification: G21; G28; G34 


\section{Introduction}

Mergers and acquisitions (M\&As) in the banking industry have attracted intense empirical research attention. Indeed, since the 1980s, when the banking sector started to consolidate and transform, the empirical literature on bank M\&As has grown exponentially, mainly with the aim of identifying and explaining the forces driving M\&As and the financial performance of the merging firms. ${ }^{1}$ One of the most popular and robust hypotheses used by the literature to rationalize the determinants of bank M\&As is the "inefficient management" hypothesis. There are two fundamental premises of this hypothesis: first, weak bank management leads to and is reflected in an inferior operating performance; second, the likelihood of an M\&A is inversely related to the quality of a bank's management, precisely because M\&As are used as a means to replace inefficient management, transplant the acquirer's superior managerial skills and restore the target bank's performance (e.g., Hannan and Rhoades, 1987; O’Keefe, 1996; Focarelli et al., 2002; Pasiouras et al., 2007; Hannan and Pilloff, 2009; Hernando et al., 2009; Caiazza et al., 2012; Beccalli and Frantz, 2013).

The literature so far has employed accounting profitability and cost management, as well as operational efficiency measures, as proxies for inefficient bank management. However, reviewing the U.S. bank examiners' reports following on-site audits offers two appealing inferences that pave the way for approaching and assessing bank management inefficiency in a different manner. First, bank management inefficiency, as reflected in serious internal organization/governance weaknesses (most notably deficient loan portfolio policies and inadequate risk management systems), is the core cause of asset quality and earnings/profitability problems that result in the erosion of banks' financial conditions and the triggering of severe formal enforcement actions. Second, and closely associated with the previous inference, such

\footnotetext{
${ }^{1}$ For an overview, see Berger et al., 1999; Amel et al., 2004; Jones and Critchfield, 2005; DeYoung et al., 2009.
} 
actions against banks for financial soundness reasons and internal organization/governance deficiencies constitute the outcomes of supervisory examination processes.

Empirical research has corroborated that formal enforcement actions possess and communicate new information on punished banks' (financial) vulnerabilities that is not already publicly available (e.g., Peek et al., 1998; Berger and Davies, 1998; Flannery and Houston, 1999; Jordan et al., 2000; DeYoung et al, 2001). The underlying reason is precisely that bank examiners have access (via bank on-site audits) to new, proprietary bank information that is more comprehensive and timelier than the publicly available information on the audited banks' safety and soundness. The most prevalent formal enforcement actions include: cease and desist orders; written agreements; suspension, removal, and prohibition orders; civil money penalties; prompt corrective action directives; safety and soundness orders; and capital directives. The actions incorporate and reveal the confidential findings of bank examinations regarding the unsound practices of punished banks' management (see also Seballos and Thomson, 1990; Gilbert, 1993; Jordan et al., 2000; Brunmeier and Willardson, 2006). Essentially, therefore, formal enforcement actions for financial soundness reasons and internal organization/governance failures are caused by and thus manifest the punished banks' management inefficiency.

This analysis stimulated our idea to assess bank management inefficiency through a novel and, we believe, more hands-on and pragmatic approach. We hand collect all formal enforcement actions issued by the three federal banking supervisors - the Federal Reserve Board (FRB), the Federal Deposit Insurance Corporation (FDIC), and the Office of the Comptroller of the Currency (OCC) - against U.S. banks over the period of 2000-2014. Informal actions are excluded because they are strictly confidential and thus not known by the market. We elaborate our initial dataset of enforcement actions to identify only formal enforcement actions signaling more directly the supervisors' assessments of the punished banks' managerial efficiency. To this end, we examine the underlying rationales of formal enforcement actions one by one, and on the basis of their reasons and the causes of the factual bases, we create two classes of actions: Class 1 enforcement 
actions include actions undertaken for financial safety and soundness reasons (e.g., capital adequacy and liquidity, asset quality, provisions and reserves, large exposures and exposures to related parties); Class 2 enforcement actions comprise actions undertaken for weaknesses relating to banks' internal organization/governance (e.g., internal control and audit systems, risk management systems, and money laundering and foreign assets control). Considering that financial safety problems and internal organization/governance weaknesses are traced to and caused by the poor quality of management decisions and practices, we contemplate that formal enforcement actions seeking to address the aforementioned weaknesses (Class 1 and 2 actions) manifest and communicate to the market new value-relevant information on punished banks' management quality.

We, therefore, test the "inefficient management" hypothesis from a distinct and original perspective. First, we assess whether and to what extent Class 1 and 2 formal enforcement actions reflecting punished banks' managerial inefficiencies affect the probability that these banks become targets of M\&As, above and beyond the observable information on the banks' characteristics and financial conditions (Hypothesis I). Second, we further assess whether the acquisition of punished vs non-punished banks generates value in the form of an improved operating performance for the combined entity (Hypothesis II).

Our analysis focuses on acquisition cases involving, almost exclusively, non-public commercial banks, in which the charter of the targets has been discontinued, while excluding acquisitions within the same bank holding group. While Granja et al. (2017) assessed the FDIC Purchase and Assumption resolution method of failed banks and reported that it entails nonnegligible misallocation costs, we concentrate solely on non-government-assisted or -forced acquisitions of punished (but not failed) banks, and we review the potential benefits of their acquisitions. To examine the acquisition likelihood of punished banks, we estimate a logit model and verify our findings by also employing alternative econometric specifications and instrumental variable techniques, treating the punished bank dummy variable as endogenous and using as an 
instrument the Gender of Supervisor's Bank Examiners, following Delis et al. (2017). This instrument enables us to measure the explicit effect of Class 1 and 2 formal enforcement actions on the probability of punished banks' acquisition, above and beyond the punished banks' characteristics and financial conditions. To examine the change in the operating performance of the newly formed entity, we employ methodological approaches that closely follow the relevant literature (e.g., Cornett et al., 2006; DeLong and DeYoung, 2007) and also employ propensity score analysis.

We find that Class 1 and 2 actions increase the probability of punished banks' acquisitions by $0.7 \%$ - and by (up to) as much as $2 \%$ and $1.6 \%$ when the acquirer or the target, respectively, belongs to a BHC group - corresponding to a $184 \%$ increase in the unconditional mean likelihood that punished banks become acquisition targets. A similar pattern is identified for the financial crisis period of 2008-2009 as well as for the periods before and after the crisis. This result implies that formal enforcement actions contain a distinctive informational value regarding punished banks' managerial resources that significantly influences potential acquirers' motives. The impact of such actions on making the decision to acquire a (punished) bank is more significant than other factors - including the target bank's inefficiency (proxied by accounting variables), size, credit expansion and asset management - which have traditionally been considered by the literature to be key determinants of bank M\&As. We also obtain appealing results regarding the postacquisition operating performance of the combined entity following M\&As, where the target banks have been punished with Class 1 and 2 formal enforcement actions. More specifically, we find significant operating performance benefits for the post-acquisition combined entity compared not only to the M\&As of non-punished target banks but also to banks not engaged in M\&As during the sample period. These findings are consistent with the premise that punished banks' M\&As serve as a means to replace inefficient management and restore the performance of their acquired assets. 
Our work is inspired by the seminal research of Mitchell and Lehn (1990) who document that value-decreasing acquisitions deals - perceived as a measure of poor managerial performance - increase the probability of the bidding firms being subsequently acquired (see also, Lehn and Zhao, 2006; Offenberg, 2009; Offenberg et al., 2014). However, our paper differs in two key, aspects, which also summarize the basic contribution of our analysis and findings. ${ }^{2}$

First, our study focuses on banks - as opposed to firms, in general - because banks are "special firms" bearing distinctive characteristics that influence the M\&A mechanism (e.g., Herring and Santomero, 2000; Devriese et al., 2004; Mullineux, 2006; Becht et al., 2011). In a nutshell, the opaqueness of banks' balance sheet - compared to other (nonfinancial) firms augments informational asymmetries and undermines both the monitoring incentives of equity and debt holders as well as the disciplinary efforts of potential acquirers. Moreover, because of the opacity of banks' assets and due to the vital role that banks play in the economy (i.e., loan origination, provision of payment services and deposit issuance), the banking industry is much more heavily regulated than other corporate sectors, which further complicates the disciplinary mechanism of the market for corporate control in the banking market (e.g., the deposit insurance regulation undermines the monitoring incentives of depositors, whereas the lender of last resort policies induce bank management to take excessive risks, thus increasing banks' risk of default). All in all, competitive forces that, in other industries, help discipline managers through the threat of M\&As are relatively much weaker and more compound in the banking industry (e.g., Caprio and Levine, 2002; Levine, 2004; Mehran et al., 2011; De Haan and Vlahu, 2016). It is no surprise, therefore, why bank supervisors are conventionally viewed as being delegated by depositors and the public, at large, the authority to monitor and discipline banks (Bliss, 2004).

\footnotetext{
${ }^{2}$ Our work also differs from this strand of literature that uses prior acquisition history as a measure of managerial performance in two, additional respects: (a) in our sample, only about $8.5 \%$ of target banks (whether of punished or non-punished targets) have been engaged in prior acquisition deal; and (b) target banks in our sample are absorbed not divested - by acquiring banks.
} 
Second, and closely related to the previous point, while the relevant literature focuses on stock price performance (or/and management turnover) to measure managerial inefficiency and market discipline, our research employs formal enforcement actions that have been taken against (nonlisted, mainly) banks by "delegated monitors", that is, by bank supervisors, for serious financial and internal governance problems as a conduit of new, value-relevant information on punished banks' management quality. Thus, we are the first, to the best of our knowledge, to explore whether bank supervisors initiate - through public disclosure of serious formal enforcement actions - an efficient information revelation mechanism that induces or assists the market to discipline and restore punished banks' inefficient management. Stated differently, we employ a different and novel measure of managerial inefficiency which, we consider, matches more effectively the distinctive characteristics of the banking industry and possesses significant explanatory and predictive power concerning (punished) banks' absorption under an M\&A transaction.

In addition, our work could be placed within the broader context of the research assessing the relationship between M\&As and the availability of (high-quality) target firm-specific information. Amel-Zadeh and Zhang (2015) showed that firms recently filing financial restatements are significantly less likely to become takeover targets - as a result of augmented adverse selection risk - than a propensity score-matched sample of non-restating firms. Marquardt and Zur (2015) documented that target firm accounting quality is positively associated with the likelihood that the proposed M\&A deal is ultimately completed. Finally, Martin and Shalev (2017) found a positive association between pre-acquisition target firm-specific information and acquisition efficiency.

The most important contribution and novelty of our study is that we provide evidence on a truly uncharted segment of M\&As in the banking industry: this study is the first that assesses the relationship between formal enforcement actions (Class 1 and 2) that communicate to the market new value-relevant information on punished banks' managerial inefficiency and the probability of punished banks' acquisition. Stated differently, our research employs and applies an original 
measure (i.e., formal enforcement actions) of managerial inefficiency to an industry (i.e., banking) with distinctive business and corporate governance features posing unique M\&A challenges; as such, our paper assesses a truly uncharted area in the wider field of banks' M\&As and enhances the breadth and depth of the "management inefficiency" theory in the M\&A literature. The validity of this novel approach to employing Class 1 and 2 actions as an identification tool for punished banks' managerial inefficiency is corroborated by our analysis (Figure I), showing that such target banks display a significantly inferior operating performance compared to non-punished target banks over a two year period preceding the acquisition.

The remainder of the paper is organized as follows. Section 2 provides an overview of the U.S supervisory enforcement mechanism and derives the testable hypotheses. Section 3 establishes our sample and data. Section 4 describes the empirical setup of the paper and presents our findings. Finally, section 5 concludes.

\section{Supervision of U.S. commercial banks and derived hypotheses}

\subsection{The U.S. banking supervision and enforcement mechanisms}

The three federal banking agencies (FRB, FDIC, OCC) supervise U.S. depository institutions (banks and savings associations/thrifts) through a combination of an on- and off-site surveillance programs. Off-site monitoring comprises the assessment of reports (i.e., the quarterly Reports of

Condition and Income (Call Reports)) that banks file with their supervisors. On-site audits constitute the cornerstone of the supervisory process. The rule is that the appropriate federal banking agency conducts, not less than once during each twelve-month period, a full-scope, onsite examination of each insured depository institution. ${ }^{3}$ In a full-scope examination, an overall and in-depth assessment of the institution's activities is conducted to evaluate an institution's capital, assets, management, earnings, liquidity, and sensitivity to market risk, - which comprise

\footnotetext{
${ }^{3} 12$ USC 1820(d)(1).
} 
the components of the Uniform Financial Institutions Ratings Systems (UFIRS) or CAMELS rating system - as well as its adherence to laws and regulations.

Under the UFIRS/CAMELS, all depository institutions are assigned a composite rating on the basis of the evaluation of these six components. Composite and component ratings are based on a scale from one (1) to five (5). A composite rating of 1 or 2 implies that any identified weaknesses are minor and can be handled routinely by the board of directors and the management ("in substantial compliance with laws"). A composite rating of 3 or 4 suggests a combination of moderate to severe or critical weaknesses, as well as that the management might lack the ability or willingness to effectively address deficiencies within appropriate timeframes ("probably in significant non-compliance with laws"). Finally, a composite rating of 5 exhibits extremely unsafe and unsound practices, resulting in critically deficient performance, as well as that the volume and severity of problems are beyond management's ability or willingness to control or correct ("in significant noncompliance with laws").

Considering the crucial role of on-site examinations in accurately identifying existing and emerging risks and developing appropriate corrective measures, bank examiners are statutorily empowered to access all of the records and employees of a bank during an examination and to conduct a thorough examination of the bank's affairs. For example, bank examiners: investigate the adequacy of a bank's internal policies regarding "cash accounts"; evaluate management's estimates of losses existing in the bank's loan portfolio, as well as the methodologies and procedures used in making and documenting the estimates; review the bank's credit files (which, typically, include financial statements, credit reports, collateral-inspection documents, reference letters, past loan applications, memoranda, correspondence, and appraisals); determine whether entries into capital accounts are appropriate and properly authorized; assess controls over offbalance sheet items; and review the accuracy of the bank's calculation of risk-weighted assets. Bank examiners document their findings and their assessment of CAMELS components in a report (report of examination - ROE). The ROE is highly confidential; although a copy is provided to 
the audited bank, this copy remains the property of the banking supervisor. The same rule applies to the composite and component CAMELS ratings determined by the federal supervisor: they are disclosed to an institution's board of directors and senior management but are not publicly disclosed.

When banks' examinations identify unsafe or unsound practices or violations of the law, banking supervisors have the authority to use enforcement actions. Under the U.S. banking supervision system, enforcement actions can be informal and formal. Informal enforcement actions comprise commitments, board resolutions, approved safety and soundness plans, and memoranda of understanding. Informal actions are not legally enforceable or publicly available, and they are reserved for relatively less significant types of misconduct and for banks with composite CAMELS ratings of 1, 2 or occasionally 3 .

Formal enforcement actions, by contrast, are statutorily authorized or mandated, are legally enforceable, and are publicly disclosed. Formal actions are considered: when informal actions prove inadequate or ineffective; when a bank receives a composite CAMELS rating of 4 , 5, or occasionally 3; or when the severity of the misconduct calls for a less cooperative and more drastic, definite, and direct supervisory intervention to constrain the bank management's room to maneuver. ${ }^{4}$ Bank examiners' findings, assessments and recommendations serve as the supervisors' primary supporting evidence for formal actions; hence, formal enforcement actions constitute the outcomes of bank examination processes and reflect bank examiners' discoveries and judgments regarding audited banks' weaknesses and deficiencies (e.g., Brunmeier and Willardson, 2006; Deloitte Center for Financial Services 2015; Jordan et al., 2000; Gilbert, 1993). ${ }^{5}$

We focus on formal enforcement actions that expose financial safety concerns and internal organization/governance problems (Class 1 and 2 actions, respectively) because such actions

\footnotetext{
${ }^{4}$ Fed (2018), s. 5020.1; FDIC (2018), s. 13.1, 14.1, 15.1; OCC (2018).

${ }^{5}$ Fed (2018), s. 5020.1; FDIC (2018), s. 15.1; OCC (2018).
} 
manifest more directly and clearly punished banks' management inefficiency. True, both the FSB (2018) and the G30 (2018) reported that bank management failure to establish efficient governance frameworks (e.g., ineffective internal reporting, insufficient internal control functions, inadequate risk management systems) generates unhealthy cultural norms, undermines banks' financial soundness and eventually leads to supervisory intervention or even bank failures. On the same line, Seballos and Thomson (1990) found that the ultimate determinant of banks' financial predicaments and failures is the inability of their management to operate internal governance mechanisms to evaluate and control risk efficiently. In their more recent research, Nguyen et al. (2016) inferred that the advising and monitoring quality of a bank's board plays a key role in the implementation and oversight of an effective internal governance system that sustains the bank's financial soundness, mitigating the risk of misconduct and reducing the likelihood of supervisory intervention.

Finally, the U.S. Government Accountability Office $^{6}$ (GAO) Reports and Recommendations on the effectiveness of federal bank supervisors' enforcement activities, offer even more direct evidence and compelling arguments that Class 1 and 2 actions encompass and communicate to the market new, value-relevant information on punished banks' management inefficiency. Indeed, GAO Reports confirm that bank management inefficiency is predominantly manifested in the failure to operate an effective internal organization/governance system (i.e., the reason for Class 2 actions) and that such failure is the root cause of serious financial safety predicaments (i.e., the reason for Class 1 actions) (e.g., GAO 93/12-14; GAO 15/365). According to GAO reports, inadequate loan portfolio policies (e.g., excessive growth objectives and imprudent lending practices, inefficient loan documentation and credit analysis procedures, deficiencies in credit and collateral files) and inefficient risk management systems (e.g., improper

\footnotetext{
${ }^{6}$ The U.S. GAO is an independent agency that works for Congress and provides objective and reliable information to help the government work more efficiently.
} 
oversight of the risks associated with high lending concentrations and excessive credit expansion, inadequate supervision and detection of weak underwriting standards, material understatement of loan loss reserves) constitute the most prominent and common manifestations of ineffective internal organization/governance systems. Moving one step further, GAO Reports depict the typical "path" through which internal organization/governance deficiencies of the type mentioned above undermine the financial soundness of banks: such weaknesses cause significant loan concentrations and excessive volumes of classified assets that erode the asset/loan quality and generate large loan loss provisions; as a result, the earnings and profitability are impaired, and eventually, the banks' capital levels are depleted.

\subsection{Testable hypotheses}

The preceding discussion of the amplified informational content of formal enforcement actions leads to two crucial inferences for our analysis. First, bank management inefficiency constitutes the fundamental cause of (and is primarily and directly reflected in) banks' internal organization/governance weaknesses and financial safety predicaments; second, formal enforcement actions for organization/governance and financial safety reasons (Class 1 and 2) incorporate the supervisory examinations' confidential findings on and assessment of punished banks' management inefficiency, thus communicating new information.

Consequently, we empirically examine the following two issues:

First, we explore whether and to what extent Class 1 and 2 formal enforcement actions on banks reflecting punished banks' managerial inefficiencies affect the probability that punished banks become targets of M\&As, above and beyond the observable information on the banks' characteristics and financial conditions (Hypothesis I). That is, after controlling for the macroeconomic (using time dummies) and bank-specific (e.g., capital strength, earnings and their volatility, efficiency, liquidity, market share) characteristics that the existent literature considers the key driving factors of bank M\&As (e.g., Wheelock and Wilson, 2000; Hannan and Pilloff, 
2009; Beccalli and Frantz, 2013), we examine whether the announcement of severe formal enforcement actions conveys distinctive information that increases potential acquirers' appetites to purchase punished banks over the two years after punishment.

Second, we assess whether the acquisition of punished vs non-punished banks generates value in the form of an improved operating performance for the combined entity (Hypothesis II). This hypothesis is founded on the "management inefficiency" premise, according to which bank M\&As are basically used by acquirers to drive out the management of poorly run banks and to exploit the target bank's full performance potential.

\section{Sample and data}

\subsection{Formal enforcement actions}

We construct our sample by hand collecting data from the websites of the three U.S. banking supervisors on all of the formal enforcement actions against commercial banks over the period of 2000Q1-2014Q4. We exclude supervisory decisions that do not contain some type of reprimand for violation of laws and/or regulations (e.g., modification/termination of prohibition orders, denial of acquisition of control, voluntary termination of insurance, interlocutory reviews, termination of cease and desist orders, etc.).

In a second step, we cleanse our initial dataset of formal enforcement actions by identifying actions that signal more directly the supervisors' assessments of punished banks' managerial inefficiency. To this end, we review, on a one-by-one basis, the texts of formal enforcement actions and examine their underlying rationales. In this way, we are able to detect the specific breach of law and the causing factual basis that led to the imposition of each formal enforcement action in our sample. Thus, we create two classes of actions: Class 1 enforcement actions encompass actions undertaken for financial safety and soundness reasons, that is, for violation of the financial safety requirements, including most notably requirements on capital adequacy and liquidity, asset quality, provisions and reserves, large exposures and exposures to related parties; Class 2 enforcement 
actions comprises actions undertaken for weaknesses relating to banks' internal organization, that is, for breaches of internal governance requirements, including most notably requirements concerning internal control and audit systems, risk management systems, money laundering and foreign assets control.

The next step is to match the name, city and state of the punished banks with the financial characteristics data from the FFIEC 031/041 Call Reports, which include all commercial banks in the U.S. for the period of 1999Q1-2015Q4, i.e., a dataset of 525,384 bank-quarter observations. ${ }^{7}$ The matching is conducted on a bank-quarter basis according to the date that the formal enforcement action becomes effective ("effective date"). If there is any discrepancy in this matching, we then drop the relevant enforcement action from the sample. Finally, we construct the Punished with Class 1/2 Enforcement Action dummy variable, which takes the value of one for the eight quarters after the quarter during which an enforcement action of Class 1 or 2 is imposed on a bank and zero otherwise.

Table I, Panel A, provides descriptive statistics per year for the enforcement actions of Classes 1 and 2, as well as for the Punished with Class 1/2 Enforcement Action variable. There is a total of 2,766 Class 1 and 2 formal enforcement actions during the 2000-2014 period in our dataset. Class 1 actions are the larger group (i.e., 2,264 cases), whereas Class 2 is the smaller group (502 cases). The number of punished bank-quarters is 16,538 .

[Insert Table I around here]

\subsection{Mergers and acquisitions}

\footnotetext{
${ }^{7}$ Online Appendix IV.A provides the details of the construction of our dataset concerning call reports data. The timeframe of the call reports data is extended to 1999Q1-2015Q4 to allow for an annual (four-quarter) window around the events.
} 
Data on commercial bank M\&As are derived from the Federal Reserve Bank of Chicago website. Bank M\&As are classified into five categories: charter discontinued, split, sale of assets, each charter retained and failure. Only cases classified as charter discontinued (i.e., the target ceases as head office, and its charter is discontinued) are considered. We proceed to a series of "refining" procedures, which include dropping targets with more than one acquirer on the same effective date and targets that are part of the same Bank Holding Company (BHC) group as the acquirer (i.e., corporate reorganizations) on the date on which the deal occurred, to create a "clean" sample containing only M\&A deals resulting in changes in control. ${ }^{8}$ Then, we merge the data on M\&As with the data on Class 1 and 2 formal enforcement actions and the call reports data. ${ }^{9}$ In almost all cases, the call report data for the target bank covering the quarter that the M\&A deal becomes effective (completion date) are not available because the target's charter is discontinued. Thus, we match with the quarter preceding the effective quarter of the M\&A deal (hereafter, we refer to this preceding quarter as the effective quarter of the M\&A deal). We then construct the Target dummy that equals 1 for this quarter and 0 otherwise, which is our main dependent variable in the context of Hypothesis $I$.

As Panel B in Table I reports, there are 2,017 bank M\&As for the period of 2000-2014 in our dataset. A total of 210 cases, i.e., approximately $10 \%$ of M\&As, concern target banks for which the Punished with Class 1/2 Enforcement Action dummy variable has the value of 1 in the quarter in which the M\&A deal becomes effective. Out of these 210 punished target M\&A cases, 199 cases concern target banks that have been punished once with Class 1/2 enforcement action during

\footnotetext{
${ }^{8}$ We follow previous studies (e.g., Cornett et al. 2006; Hannan and Pilloff, 2009) and employ the "change-in-control” standard, according to which a deal is considered to be an acquisition if, in the pre-acquisition period, the acquiring firm does not possess or possesses a very small percentage of ownership in the target institution.

${ }^{9}$ Online Appendix IV.B provides the details of the construction of our dataset concerning bank M\&As and the matching procedure with the call reports and enforcement actions data.
} 
the eight quarters period prior to the M\&A transaction and 11 cases concern target banks that have been punished twice.

Figure 1 shows the cross-sectional median of the industry-size-adjusted $\mathrm{ROA}^{10}$ during the eight quarters preceding the quarter in which the M\&A becomes effective (denoted as $\mathrm{t}=0$ in the horizontal axis) for: a) target banks punished with Class $1 / 2$ formal enforcement actions; b) nonpunished target banks. As is apparent from this Figure, punished target banks exhibit low and persistently declining performance in the pre-M\&A period, well below that of non-punished banks. Wilcoxon's rank-sum test results (available upon request) show that the difference in the (median) industry-size-adjusted ROA between the punished and non-punished target banks is significantly different from zero at the $1 \%$ level of significance for each of the eight quarters in the pre-M\&A period. Essentially, Figure 1 confirms that Class 1 and 2 formal enforcement actions do produce a division between the group of punished and non-punished target banks in terms of their performance - potentially because such actions incorporate additional value-relevant information about the underlying reasons for punished banks' continuing performance decline and thus regarding the poor prospects of future recovery.

[Insert Figure I around here]

We further expand our analysis to reveal the initiating party of the M\&A deals. We collect information from the Capital IQ database, provided by S\&P Global Market Intelligence, regarding whether the M\&A deals are characterized as "Solicited" or "Unsolicited". ${ }^{11}$ Of the 2,017 M\&A cases, we were able to retrieve this information for 1,053 deals: 893 deals concern non-punished targets, and 160 cases relate to Punished with Class 1/2 Enforcement Action target banks. With

\footnotetext{
${ }^{10}$ The picture is similar when we graph the industry-size-adjusted operating pre-tax cash flow ROA (OPCFROA).

${ }^{11}$ We use the link between the Capital IQ M\&A deal IDs and the SNL deal IDs for matching; they were kindly provided to us by Capital IQ.
} 
respect to the former group, that is, M\&As involving non-punished target banks, approximately 92.2\% are unsolicited, and the same goes for approximately $88.8 \%$ of the M\&A deals involving punished target banks. The mean-comparison test of a dummy variable Deal approach (which takes the value of 1 when the M\&A deal is "Unsolicited" and 0 otherwise) between the two groups of target banks, i.e., non-punished vs punished, shows that their difference is not statistically different from zero at conventional levels of significance.

In a nutshell, we find that the management of target banks punished with Class 1 or 2 enforcement actions is no more likely to shop the acquirer than the management of non-punished target banks. Moreover, this evidence corroborates that it is the acquirer that observes an inefficient and weakened rival and thus takes the initiative to launch the M\&A deal. Essentially, this finding does not lend support to the theory advanced by part of the literature (e.g., Milne, 2002; Koetter et al., 2007; Kjellman et al., 2014) suggesting that it is the punished bank that typically shops around for potential acquirers.

\section{Empirical analysis and results}

\subsection{Acquisition likelihood of punished banks}

\subsubsection{Main model specification and results}

To examine the probability of punished banks' acquisition (Hypothesis I), we estimate a discrete choice model with logit specification of the following form:

$P\left(\right.$ Target $\left._{i, t}=1 \mid \mathbf{X}\right)=G\left(a+a_{1}\right.$ Punished with Class $1 / 2{\left.\text { Enforcement } \text { Action }_{i, t}+\beta X_{i, t-m}\right)}$

The Punished with Class 1/2 Enforcement Action dummy is the core variable of interest. $X_{i, t-m}$ comprises bank-specific variables, applied to bank $i$ at quarter $t$ - $m$, that affect the acquisition likelihood of the bank. Two variations of equation (1) are estimated: In the first one, the vector $X_{i, t-m}$ includes the variables that the prior literature (e.g., Wheelock and Wilson, 2000; Hannan and Pilloff, 2009; Beccalli and Frantz, 2013) has shown to influence acquisition likelihood 
(henceforth, "Literature" model). In the second model, we add to the vector $X_{i, t-m}$ additional bankspecific variables aiming to reflect the CAMELS ratings' components (henceforth, "Enhanced" model).

Thus, in the vector $X_{i, t-m}$, we consider leverage and capital strength, measured by the equity to assets ratio and the risk-based capital ratio, respectively. We measure asset management using different variables: the loan to assets ratio, which captures credit expansion; the riskweighted assets ratio, which measures credit risk; the non-interest income ratio, which accounts for a bank's divergence from traditional banking activities; and the non-performing loans ratio, which reflects the quality of the loan portfolio. As a proxy for earnings and their volatility, we include Operating Pre-Tax Cash Flow ROA (OPCFROA) and the standard deviation of Operating Pre-Tax Cash Flow ROA ( $\sigma(O P C F R O A)$ over 12 quarters. ${ }^{12}$ Banks' liquidity and funding structure are approximated by the liquidity ratio and the deposits to assets ratio, respectively. Managerial inefficiency is closely associated with and reflected in our performance measures, yet we also use inefficiency, defined as the ratio of total non-interest expenses to the sum of total interest and non-interest income minus total interest expenses, and the net interest margin ratio as additional supplements to approach the "M" component of the CAMELS ratings. Other measures that the literature has revealed to influence the probability of bank M\&As include the bank's size, market share and age. We also employ the binary variable Multi-state dummy, which identifies whether banks have branches operating in multiple states during a given quarter. Part I of Table I in the Online Appendix provides more details on all of the variables considered in the analysis, whereas Part I of Table II presents their summary statistics.

[Insert Table II around here]

\footnotetext{
${ }^{12}$ In alternative specifications, we employ the ROA and $\sigma(\mathrm{ROA})$ instead. The results remain valid.
} 
We estimate equation (1) using two different values of $m$, i.e., 8 and 4 , in a first effort to insulate the influence of the target banks' financial condition on the probability of acquisition from the impact of Class 1 and 2 enforcement actions on the deal. ${ }^{13}$ Time dummies, to control for the macroeconomic environment and common shocks that banks face, are included in all of the regressions. Estimation is performed with robust standard errors clustered by bank.

The results of this analysis are reported in Table III. Panels A and B report the marginal effects of the variables employed in the "Literature" and the "Enhanced" models, respectively.

[Insert Table III around here]

Briefly, the two models show that more leveraged (equity to assets ratio) as well as less capitalized (risk-based capital ratio) and less profitable (OPCFROA) banks are more likely to become acquisition targets. On the same line, the probability of acquisition is positively associated with less efficient (inefficiency, net interest margin) or more liquid banks (liquidity ratio), and the same association applies to younger banks and banks with lower market share. By contrast, the probability of being acquired is less for banks that rely relatively more on deposits to fund their asset side (deposits to assets ratio), as well as for banks with better loan portfolio quality (nonperforming loans ratio) and for banks with more developed non-interest business lines (noninterest income ratio). However, the most important finding is that the main explanatory variable (Punished with Class 1/2 Enforcement Action) maintains its statistical and economic significance after having incorporated and considered in our models a large array of control variables.

More specifically, as Table III indicates, the marginal effect of the Punished with Class 1/2 Enforcement Action dummy is positive and strongly significant at the $1 \%$ level in both the "Literature" and "Enhanced" models and for both variants of the control variables' lag structure.

\footnotetext{
${ }^{13}$ The findings are similar when we employ the control variables lagged by one quarter as well as when we include (one by one) various lags of the (y-o-y) change in performance measures.
} 
According to the reported marginal effect, banks that received Class 1 or 2 formal enforcement actions have increased by $0.7 \%$ their probability of becoming acquisition targets in the two years following the enforcement action. Given that the unconditional probability of a bank becoming a target during our sample period is $0.38 \%$, this finding corresponds to an approximately $184 \%$ increase. More importantly, we find that the Punished with Class 1/2 Enforcement Action variable is ranked as the fourth determinant of bank acquisition, following in order leverage (equity to assets), profitability (operating cash flow) and liquidity (liquidity ratio), which are considered "conventional" driving factors of bank M\&As. ${ }^{14}$

\subsubsection{Omitted variables and endogeneity concerns: alternative econometric specifications}

To confirm the validity of our results, we re-estimate equation (1) using the linear probability model and including bank fixed effects to capture the potential time invariant bank characteristics not already controlled for that can affect the likelihood of acquisition. ${ }^{15}$ The results are reported in the first column of Table IV. The coefficient of Punished with Class 1/2 Enforcement Action dummy remains strongly significant, whereas its magnitude is similar to the marginal effect obtained in our baseline results in Table III.

[Insert Table IV around here]

\footnotetext{
${ }^{14}$ We also estimated equation (1) by employing a variant of the Punished with Class 1/2 Enforcement Action - 1 year dummy variable, which has a value of 1 for the four subsequent quarters after the quarter during which a Class 1 or 2 enforcement action is imposed on a bank and has a value of 0 otherwise. The results, reported in the Online Appendix, Table II, remain intact.

${ }^{15}$ For this and the remaining estimations in this part of the analysis, we keep the "Literature" model because it is parsimonious and only use the set of bank-specific controls $X_{i, t-4}, i . e$., lagged four quarters. The results of the "Enhanced" model or when we employ eight (or one) lags for the control variables (available upon request) are similar.
} 
A more significant concern is that endogeneity can arise due to the inability to observe how punished target banks would have behaved in the event of not receiving an enforcement action. Moreover, endogeneity can stem from non-punished target banks, which should have otherwise been punished. A potential scenario for the latter remark could be that a poorly performing bank, expecting to receive an enforcement action, might decide to seek potential acquirers as a "remedial strategy" to avoid punishment. Furthermore, enforcement actions could reflect punished target banks' financial weakness, not captured by the set of control variables and/or their lag structure in equation (1) (omitted variables bias). To address such concerns we employ a two-stage instrumental variable (IV) model of the following form:

Punished with Class 1/2 Enforcement Action f $_{i, t}=b_{0}+b_{1} z_{i, t-4}+b_{2} X_{i, t-4}^{\prime}+e_{i, t}(2)$ Target $_{i, t}=a_{0}+a_{1}$ Punished with Class $\overline{1 / 2}$ Enforcement Actıon ${ }_{i, t}+a_{2} X_{i, t-4}+u_{i, t}(3)$

In the first stage equation (2) (treatment equation) the dependent variable is the Punished with Class 1/2 Enforcement Action dummy. $X^{\prime}{ }_{i, t-4}$ is a vector of co-variates that consists of bankspecific and macro-economic variables, as in Delis et al. (2017). Therefore, $X^{\prime}{ }_{i, t-4}$ includes a set of proxies of the CAMELS ratings' components that affect the likelihood of being punished for bank $i$ at $t$, i.e., the risk-based capital ratio, the risk-weighted assets ratio, ROA and $\sigma(R O A)$, the non-interest income ratio, the non-performing loans ratio, the liquidity ratio, the trading securities ratio and the FDIC dummy for FDIC-supervised banks. The additional macro-variables considered in the vector $X_{i, t-4}^{\prime}$ are the effective funds rate, the GDP growth (y-o-y) and the financial stress index. Equation (3) is the second stage equation in which $X_{i, t-4}$ is the vector of bank-specific covariates also employed in equation (1), which affects the acquisition likelihood, accompanied by a full set of time (quarter) dummies.

Following Delis et al. (2017), we select the Gender of Supervisor's Bank Examiners as the instrumental variable $z_{i, t-4}$ in equation (2) using data from the Fedscope Employment Cubes, which are available online from the Office of Personnel Management. We retrieve the information 
on the gender of bank examiners for the FDIC and the OCC on a state-year basis (state-quarter from 2007Q3 onward), and we calculate the gender variable as the ratio of female examiners to the total number of the bank examiners for each supervisor per state and year (by quarter when available). Hence, this analysis is restricted to the FDIC- and OCC-supervised banks in our sample. To further refine the instrument, pre-first stage regressions are performed on the calculated gender variable. The purpose of running the pre-first stage regressions is to remove trends and statespecific socio-economic and demographic characteristics from the instrument that could potentially violate the exclusion restriction property. To this end, for each supervisory authority, the gender variable is regressed on state fixed effects and time quarter dummy variables. The error term from these regressions is obtained as our instrument $z_{i, t-4}$ in equation (2). Finally, we match the instrument to the banks in our sample using, apart from the year (quarter), the state in which each bank is headquartered for the OCC-supervised banks and the state of the FDIC field office responsible for the on-site examination for each FDIC-supervised bank. ${ }^{16}$

We postulate that the Gender of Supervisor's Bank Examiners satisfies the exclusion restriction criterion; that is, it affects the likelihood of enforcement action, given the set of controls $X_{i, t-4}^{\prime}$ in equation (2), but it does not have a direct impact on the bank's probability of being acquired. The rationale for the instrument is provided by empirical evidence in the accounting literature suggesting that, compared with their male peers: female auditors are more vigilant and efficient processors of information and of complex auditing tasks; spend more time on risk assessment; place greater effort on their monitoring engagements; and improve audit quality (e.g., O’Donnell and Johnson, 2001; Ittonen et al., 2013; Hardies et al., 2016; Khlif and Achek, 2017). Thus, we expect that greater female auditors' participation in the bank examination process will yield more formal enforcement actions, ceteris paribus.

\footnotetext{
${ }^{16}$ The rule for the OCC and FDIC on-site examination audits is that they are conducted via the local supervisory field offices and are allocated to the examiners of the field office in the states in which the banks are headquartered.
} 
We estimate equations (2) and (3) with two alternative instrumental variable techniques: a) As a treatment effects model, in which equation (2) (treatment equation) is a probit model and equation (3) (response equation) is a linear model. The treatment and response equations are simultaneously estimated using the two-step consistent estimator of the parameters, whereas error terms in both equations are assumed to be normally distributed. b) As a recursive bivariate probit model, as in Minetti and Zhu (2011). The advantage of this approach is that it allows for the use of a discrete choice model (probit) for both the first and second stage regressions since our main dependent variable Target is also a dichotomous variable. ${ }^{17}$ The recursive bivariate probit model is estimated with maximum-likelihood and robust standard errors clustered by bank.

Table IV reports in the second and third columns the results obtained from these two instrumental variable techniques. The instrumental variable in the first stage probit of both models is positive and significant at the $1 \%$ level, as expected. The coefficient of interest (Punished with Class 1/2 Enforcement Action) of the treatment effects model remains highly significant, with similar magnitude to the marginal effect reported in the baseline results.

The results from the recursive bivariate probit model, presented in the third column of Table IV, show that the marginal effect of the Punished with Class 1/2 Enforcement Action dummy is $0.4 \%$ and is strongly significant. Moreover, we performed two tests of endogeneity for this model: the Wald test of rho ${ }^{18}$ (reported in the bottom of the third column) and the Durbin-WuHausman augmented regression test, with which we also included the generalized residuals (Gourieroux et al., 1987) as an additional explanatory variable. As suggested by both tests, Punished with Class 1/2 Enforcement Action is not endogenous to the probability of a bank becoming a target.

\footnotetext{
${ }^{17}$ It is important to note that, in these two instrumental variable techniques, the control variables in equations (2) and (3) do not need to be identical.

${ }^{18}$ The likelihood ratio test of whether rho equals zero can be used as a Hausman endogeneity test. Rho is the correlation coefficient between the residuals of each of the two probit models.
} 


\subsubsection{The 2007 subprime crisis}

The financial crisis period is of particular interest in our setting because it augmented uncertainty, heightened risks, exposed banks' vulnerabilities and increased the intensity of supervisory intervention. For this purpose, equation (1) is re-estimated for the period between 2007Q1 and 2009Q4. The results of this analysis, presented in the first column of Table V, show that the marginal effect of Punished with Class 1/2 Enforcement Action remains statistically significant at the $1 \%$ level for the financial crisis period, amounting to an increase in probability of a punished bank becoming a target of an M\&A of approximately $0.7 \%$. This marginal effect corresponds to a $184 \%$ increase in the unconditional probability of an M\&A during the crisis era, identical to that reported in our baseline results. Overall, we observe that Class 1 and 2 enforcement actions remain within the top-four determinants of bank acquisitions during the financial crisis period.

\section{[Insert Table V around here]}

At first glance, this result seems rather unforeseen: considering that the 2007-2009 financial turmoil was a period characterized by intensified supervisory monitoring, increased enforcement activity and amplified bank distress, we would expect that (ailing) banks' management inefficiency would be exposed in a more direct and forceful manner via Class 1 and 2 formal enforcement actions, in turn depressing prices and raising the probability of punished banks being acquired (e.g., Beltratti and Paladino, 2013; Dunn et al., 2015). That is, we would anticipate that Class 1 and 2 formal enforcement actions would possess amplified informational value during the crisis. However, it seems that this rather expected increase in enforcement actions' informational value was numbed by the augmented opacity of (punished) banks' balance sheets (e.g., on the level of mortgage-backed security holdings and non-performing loans) and the overall uncertainty during the crisis, which caused increased informational asymmetry and ambiguity (e.g., Adams, 2012; Beltratti and Paladino, 2013). 
Additionally, we consider alternative variations of sub-sample periods. Specifically, we exclude the financial crisis period and also separately examine the pre- and post-crisis periods, i.e., 1999Q1-2006Q4 and 2010Q1-2015Q4, respectively. The results of this analysis, presented in the last three columns of Table $\mathrm{V}$, show that the marginal effect of Punished with Class 1/2 Enforcement Action remains strongly significant in all cases. The tests of the equality of the marginal effects across the different sub-periods, reported in the bottom part of the Table, show that only the marginal effect for the pre-crisis period is higher than that for the post-crisis era.

\subsubsection{Sensitivity analysis}

The issuance of severe formal enforcement actions mainly serves to compel punished banks to address and restore shortcomings identified during the examination process. Indeed, as suggested by the descriptive statistics of the changes in five core financial characteristics of banks, reported in Table V in the Online Appendix, Class 1/2 formal enforcement actions induce the average punished bank in our sample to take corrective measures and raise its risk-based capital ratio; shrink its risk-weighted assets ratio; contract its loan activity; reduce its risk; and increase its $R O A$. These findings are consistent with the relevant empirical literature (Curry, 1997; Peek and Rosengren, 1995 and 1996, Caiazza et al., 2018, Danisewicz et al., 2018; Delis et al., 2017). However, the percentile values of the changes in all five variables for the punished bank-quarters show a significant variability, which suggests that not all punished banks in the sample are able (or willing) to undertake and implement corrective measures after the issuance of Class 1/2 actions.

We further explore whether the corrective measures (if any) that punished banks take following the announcement of Class $1 / 2$ actions affect the probability of being taken over. To this end, we augment equation (1) by including: i) a vector $\Delta X_{i, t-m}^{\prime}$ comprising the y-o-y changes in the risk-based capital ratio, the risk-weighted assets ratio, the non-performing loans ratio, $R O A$, and the (log) total loans; ii) the interaction term between the vector $\Delta X_{i, t-m}^{\prime}$ and the Punished with Class 1/2 Enforcement Action dummy variable. The results of this analysis, using two different 
values of $m$, i.e., 4 and 1, for both the "Literature" and the "Enhanced" model, are depicted in Figures II and III. ${ }^{19}$ The vertical axis shows the marginal effect, along with their relevant confidence intervals at the $95 \%$ level of significance, of the Punished with Class 1/2 Enforcement Action dummy variable computed at the $10^{\text {th }}, 25^{\text {th }}, 50^{\text {th }}, 75^{\text {th }}$ and $90^{\text {th }}$ percentiles of the punished bank-quarters values for each variable in $\Delta X_{i, t-m}^{\prime}$ (shown in the horizontal axis), i.e., with respect to different degrees of improvement/deterioration in the five financial characteristics of the relevant punished bank.

\section{[Insert Figures II and III around here]}

As these figures indicate, any improvement/deterioration in the punished bank's financial characteristics does not eliminate the predictive power of the Punished with Class 1/2 Enforcement Action dummy, yet, in certain cases, it significantly affects its magnitude. The two variables that seem to predominantly affect the sensitivity of the acquisition likelihood of a punished bank are the $\mathrm{y}-\mathrm{o}-\mathrm{y}$ changes from $t-5$ to $t-1$ relative to the quarter the M\&A becomes effective in the riskweighted assets ratio and, more heavily, the change in the (log) total loans. These findings are in line with the conjecture that the probability of punished banks' acquisition following the issuance of Class $1 / 2$ actions increases for punished entities that contract their loan portfolio activity and retain a larger share of risky assets relative to their total assets.

\subsubsection{Other robustness checks}

To examine whether the probability of a punished bank being acquired is affected when the target or the acquirer are members of a BHC, we re-estimate equation (1) for the sub-sample of banks engaged in M\&As as targets during the sample period and for the different ownership statuses of the acquirer or the target. The results, reported in Table IV in the Online Appendix, show that the

\footnotetext{
${ }^{19} \mathrm{We}$ also report these results in the Table VI in the Online Appendix
} 
marginal effect of the Punished with Class 1/2 Enforcement Action remains significant at the $1 \%$ level across all four specifications. Its magnitude rises to $2 \%$ and $1.6 \%$ when the acquirer or the target, respectively, belongs to a BHC group. These results indicate that Class 1 and 2 enforcement actions increase the probability of punished banks' acquisition irrespective of the ownership status of the acquirer and the target. Furthermore, as in the baseline results, the Punished with Class 1/2 Enforcement Action dummy is again ranked among the top four determinants of bank acquisition.

We also address the possibility that enforcement actions imposed on punished banks simply represent extreme cases of bad management. For example, if the effect of performance on takeover probability is non-linear, e.g., convex, it is quite conceivable that the marginal effect of Punished with Class 1/2 Enforcement Action is simply picking up this non-linearity. We explore this possibility by estimating several non-linear functional forms of equation (1) with respect to performance-related measures, i.e., OPCFROA and $\sigma(O P C F R O A)$. We also address the issue of potential non-linearity with respect to all of the variables employed in the model. The results (available upon request) show that, in all these specifications, the explanatory power and the economic significance of the Punished with Class 1/2 Enforcement Action dummy remain unchanged. Furthermore, we estimated equation (1) using only the unsolicited M\&As (see section 3.2) for the construction of the dependent variable. The results (available upon request) show that the economic and statistical significance of the Punished with Class 1/2 Enforcement Action variable is not affected.

Moreover, considering that there is a time distance between the announcement and the completion of an M\&A deal, we use the deal announcement (instead of the deal completion) date to define the dependent variable in equation (1). To this end we derive the relevant information from the SNL database and calculate a new dependent Target dummy variable that equals 1 for the target bank-quarter during which the M\&A deal (that is recorded in the SNL database) is announced and 0 otherwise. The average number of months between the deal announcement and deal completion dates is 4.67 . The associated findings (available upon request) indicate that the 
significance and economic importance of the Punished with Class $1 / 2$ enforcement action dummy remains unchanged, regardless of whether we are using the announcement date of the merger deal, instead of the completion date as the relevant event.

Overall, our results corroborate that formal enforcement actions for financial safety reasons and core internal organization/governance weaknesses (Class 1 and 2) that are caused by punished banks' management inefficiency incorporate and convey distinctive, new information - above and beyond the already observable information on banks' characteristics and financial conditions increasing potential acquirers' appetites to launch bids for punished banks. This finding is all the more true for non-listed banks - like the ones in our sample - for which financial information is not readily available, and the market for corporate control as a disciplinary mechanism for inefficient management is absent (Koetter et al., 2007; Hannan and Pilloff, 2009).

\subsection{Operating performance in acquisition deals with punished banks as targets}

The objective of this section is to examine whether the acquisition of punished banks leads to an improved operating performance of the post-acquisition combined entity (Hypothesis II) over a time frame of $(-1,+1)$ and $(-1,+2)$ years around the effective quarter of the deal. To this end, we start with the 2,017 M\&A cases in our sample, and following the relevant literature (e.g., Cornett et al., 2006; Wang and Xie, 2009), we apply two conditions that must be satisfied for an M\&A deal to be included in this part of the analysis. First, we drop M\&A deals in which the acquiring bank is involved in other deals during a time frame of $(-1,+1)$ or $(-1,+2)$ years around the M\&A. This condition is applied to eliminate the existence of confounding events that could interfere with our results. Second, only M\&A deals in which the relative size of target and acquirer is greater than $1 \%$ at the end of the year before the quarter in which the deal became effective are considered. Then, we match the information on the financial conditions of the target banks and the Class 1 and 2 formal enforcement actions against these banks to that of the acquiring banks engaged in these M\&A cases to observe the banks that participate in the pre-M\&A period and the combined entity 
post-M\&A for each deal. We also use the information on the deal characteristics for these M\&As obtained from the SNL database. ${ }^{20}$

In this way, we end up with 752 M\&A deals, of which 92 cases concern M\&As of punished target banks; these 92 cases are used to examine whether the operating performance of the combined entity after the M\&A of a punished target bank improves. ${ }^{21}$

\subsubsection{Cross-sectional analysis and results}

Following Cornett et al. (2006), we estimate the cross-sectional equation of the following form:

$$
\begin{gathered}
\Delta \text { Performance }_{i}=a_{0}+a_{1}{\text { Punished with Class } 1 / 2 \text { Enforcement Action } \text { Target }_{i}}^{+a_{2} X_{i}+a_{3} D_{i}+e_{i}}
\end{gathered}
$$

where $\Delta$ Performance $_{i}$ is the change over the $(-1,+1)$ and $(-1,+2)$ years' time frame around the deal $i$ of two industry-size adjusted performance measures: the return on assets (ROA) and the pretax operating cash flow ROA (OPCFROA). The industry-size-adjustment is conducted in terms of each bank's local market, allowing us to eliminate any (local) industry-related effects that could affect the impact of the merger on performance. We consider banks to belong to the same local market when they are headquartered within the same FDIC field office (or, in sensitivity tests, the same Fed district, as in Cornett et al. (2006)) and belong to the same asset class. We identify the peers of each bank in the local market among the banks not involved in M\&A deals in the time frame of $(-1,+2)$ years around the year in which the deal in consideration became effective. For the categorization of asset classes, we construct five alternative groups of banks, according to their total assets, with cut-off points of 100 mil., 300 mil., 1 bil. and 15 bil. USD, respectively.

\footnotetext{
${ }^{20}$ The details concerning the matching of information on M\&A deals derived from the SNL database and the Chicago FED M\&A file can be found in the Online Appendix, Part IV.C.

${ }^{21}$ We confirm that the results presented in subsection 4.1 on punished banks' acquisition likelihood (Hypothesis I) also hold for the smaller sample of target banks used to assess the second hypothesis (see Table III in the Online Appendix).
} 
The pre-acquisition industry-size-adjusted performance measure is the weighted average of the relevant performance measures of the target and the acquirer engaged in deal $i$ for the year end prior to the acquisition, using the book value of their total assets as weights. The relevant postacquisition measure is that of the combined entity for one and two years following the acquisition deal at each year end. $\Delta$ Performance ${ }_{i}$ is the difference between the pre- and post-acquisition industry-size-adjusted performance measures. Part II of Table II presents the summary statistics for these variables.

The core variable of interest in equation (4) is the Punished with Class 1/ 2 Formal Enforcement Action Target, which equals 1 if the target bank in an M\&A deal is punished with an enforcement action of Class 1 or 2 that has become effective in any of the eight quarters preceding the M\&A deal and 0 otherwise. ${ }^{22}$ The coefficient $a_{1}$ captures the difference in the dependent variable between the M\&A of a punished target vs the M\&A of a non-punished target, that is, the difference-in-differences (DiD) estimate of the impact on the industry-size-adjusted performance of the acquisition of punished compared to non-punished banks. Thus, $a_{1}$ is the estimate of the average treatment effect on the treated (ATT) (Athey and Imbens, 2006).

The vector $X_{i}$ includes a set of financial characteristics of both the acquirer and the combined entity. Specifically, we employ the acquirer's size (acquirer's total assets) at the end of the year preceding the M\&A deal. Prior studies have reported mixed evidence on the direction of this relationship. For example, Cornett et al. (2006) found a positive relationship, whereas, in a similar setting, DeLong and DeYoung (2007) reached the opposite results. We also employ the changes over the $(-1,+1)$ or $(-1,+2)$ year time frames around the acquisition deal, in accordance

\footnotetext{
${ }^{22} \mathrm{We}$ also conducted the current analysis, albeit with fewer acquisitions of punished targets, using the Punished with Class 1/2 Formal enforcement actions Target - 1 year dummy variable, which equals 1 if the target bank in an M\&A deal has been punished with a Class 1 or 2 enforcement action that has become effective in any of four quarters preceding the M\&A deal and equals 0 otherwise. The results, available upon request, led to similar inferences.
} 
with the dependent variable, of two ratios (change in equity to assets ratio and change in subordinated debt to assets ratio) indicating the bank's change in leverage and in its ability to attract loans, respectively. Cornett et al. (2006) found that an increase of the capital ratio is related to increased performance.

The vector $D_{i}$ contains information on deal characteristics. Specifically, we include two measures capturing the ratio of the market share of the target to that of the acquirer, in terms of the relative size of total assets (relative size) and number of branches (branch ratio) at the end of the year preceding the M\&A deal. We expect a positive relationship between relative size and performance (e.g., DeLong, 2001), whereas the anticipated impact of the branch ratio on performance is less straightforward. A positive sign could suggest greater post-merger performance due to increased room for synergies, whereas the opposite might as well hold since increased retail banking activities are related to significantly lower performance for U.S. banks (Hirtle and Stiroh, 2007). To identify whether the target and the acquirer operate within the same state, we include the in-state buyer dummy, anticipating a positive coefficient since geographic similarity among targets and acquirers is value enhancing (DeLong, 2001). We also use the Private Equity dummy since private equity acquisitions alter various aspects of a firm, including its profitability (Goergen et al., 2011). Finally, the cardinal variable geographic market expansion indicates whether there is complete, indicated with the value of 1 , or partial geographic overlap between the acquirer and the target. We expect a negative coefficient for this variable because the majority of studies (e.g., Cornet et al., 2006; DeLong and DeYoung, 2007) have found that performance following a merger is higher when there is geographic overlap. Further details on these variables can be found in Table I, Part II, in the Online Appendix, whereas Part II of Table II presents their summary statistics.

A full set of year dummies is included in equation (4) to account for common shocks that could affect the change in the performance measure. The estimation method of equation (4) is OLS with robust standard errors. 
Table VI presents the findings from this analysis. Panel A displays the results regarding the change in the performance measure of the combined firm in the $(-1,+1)$ year frame, and Panel B presents the relevant results in the $(-1,+2)$ year frame around the M\&A deal.

[Insert Table VI around here]

Overall, these results show that the core variable of interest, the Punished with Class 1/2 Enforcement Action Target dummy, is positive and strongly significant in all specifications, whereas the control variables bear the expected sign. When the OPCFROA performance measure is employed, the relevant coefficients are 0.0038 and 0.0049 for the $(-1,+1)$ and $(-1,+2)$ years' time frame around the $M \& A$, respectively. The economic significance of these figures is large. The first figure is twelve times higher than the relevant (unconditional) mean change in the industry-sizeadjusted OPCFROA figure for all M\&A deals, reported in Panel A of Part II in Table II. The second figure is positive, whereas the relevant (unconditional) mean change in performance for all M\&A deals is negative, and most importantly, the former is approximately sixteen times greater than the latter's absolute value. These results imply that the improvement in the operating performance of the combined firm resulting from the acquisition of a punished bank, compared with a non-punished bank, is quite larger. In unreported regressions, we also employ a variation of the performance measures, adjusted for (local) industry only - the results convey the same message.

\subsubsection{Propensity score matching}

We also employ a propensity score matching approach combined with a DiD estimator, as in Stiebale (2016). This approach allows us to address concerns regarding potential self-selection bias that could drive our findings from equation (4), without the need to use appropriate instruments. The appeal of the propensity score matching technique is that it addresses the counterfactual problem, i.e., how the artificially combined entity of the acquirer and the punished 
target would have performed in the absence of the treatment, that is, the replacement of the punished target's inefficient management through the M\&A.

To this end, we use the $92 \mathrm{M} \&$ As of punished target banks employed in the estimation of equation (4) and conduct the matching of the artificially combined entity of the acquirer and the punished target using two alternative control groups: The first comprises the artificially combined entity of the acquirer and the target in the M\&A deals of non-punished targets, i.e., 660 cases. The second comprises end-of-year data for all U.S. commercial banks not engaged in M\&As, either as acquirers or targets, during the sample period and included in the sample used in section 3.1., i.e., 67,359 bank-year observations. In this way, we are able to examine whether performance is improved following an M\&A of a punished target bank not only compared with an M\&A of a nonpunished target but also compared with a similar bank not engaged in M\&A.

For the matching, we use as controls the financial characteristics of the artificially combined entity of the acquirer and the punished target and measured at the year-end prior to the acquisition. These characteristics comprise the equity to assets ratio, the subordinated debt to assets ratio, and size (as well as relative size when the control group is the artificially combined entity of the acquirer and the target in the M\&A deals of non-punished targets). We also include the differences in these variables in the time frame of $(-2,-1)$ years before the M\&A, plus the relevant change in $R O A$, in an effort to capture the dynamics of both matched and control firms' characteristics and to improve matching. ${ }^{23}$ In the matching procedure, we employ common support, calipers and nearest neighbors, and we force the matching with control firms in the same year. The outcome variable is $\Delta$ Performance , i.e., the change over the $(-1,+1)$ and $(-1,+2)$ years' time frame of the industry-size-adjusted performance measures.

\footnotetext{
${ }^{23} \mathrm{We}$ also conduct matching to both control groups without using the differenced variables. The results (available upon request) lead to similar inferences.
} 
The propensity score estimation results and the test for the balancing property between the treated group and each control group are reported in Tables III and IV in the Online Appendix, respectively. As Table IV in the Online Appendix shows, the balancing property holds for the matched samples of the treated group, i.e., the M\&As with a punished target bank, and each control group for all of the variables.

The average treatment effect on the treated results for the outcome variable over the $(-1,+1)$ and $(-1,+2)$ years horizons are reported in Table VII. Panel A presents the results when the control group consists of banks in non-punished target M\&A deals, and Panel B reports the relevant results when the control group comprises banks not engaged in M\&As during the sample period. Standard errors are adjusted to account for the propensity score being estimated (Abadie and Imbens, 2006).

[Insert Table VII around here]

As Panel A in Table VII shows, the outcome variables are positive and statistically significant in the $(-1,+2)$ years' time frame around the M\&A. As indicated, the increase in the industry-sizeadjusted OPCFROA is higher than that in M\&As of non-punished target banks by as much as 0.0028 points. Turning to Panel B, M\&As of punished target banks exhibit higher performance changes in the $(-1,+2)$ years' time frame than that of banks not engaged in M\&As, amounting to 0.0040 points for the industry-size-adjusted OPCFROA. Thus, the argument regarding the benefits of the replacement of the inefficient management of a punished bank through the M\&A is further strengthened.

\subsubsection{Evidence on the replacement of the inefficient management in punished target banks after} the $M \& A$ deal

We also provide evidence for the replacement of the inefficient management in punished target banks after the M\&A deal. Specifically, for each of the 92 M\&A cases of punished target banks, we seek information on the board membership of the punished target at the end of the year before 
the M\&A deal and the relevant information for the combined entity after the deal. We find that: a) the combined entity's board comprised fewer than three directors from the punished target-bank in 83 cases; b) the combined entity's board comprised no directors from the punished target banks

in 49 cases. We then re-estimate equation (4) by retaining these M\&A cases with board replacement. The results for the improvement of the operating performance of punished target M\&As (available upon request) lead to similar inferences.

\subsubsection{Evidence on performance improvement from stock prices}

Our sample contains only a handful of listed banks, either as acquirers or targets. Because we are unable to examine the acquiring and target banks' Cumulative Abnormal Returns (CARs), we assess, as a surrogate, the CARs of the listed entities that are leading shareholders of the acquiring banks or the punished target banks engaged in the sample M\&As. For this analysis we: a) consider only the M\&As of targets punished with a Class 1 or 2 enforcement action publicized within 2 years, i.e., 500 trading days, before the M\&A agreement date, obtained from the SNL database; b) use the stock price data from WRDS and the PERMCO-RSSD9001 link provided by the Federal Reserve Bank of New York. We expect that the stock price response around the M\&A agreement date incorporates the market's assessment of the deals' value-creating or -destroying effect and the allocation of the welfare to acquirers or targets' shareholders. The Abnormal Return (AR) for a security $i$ on day $t$ is the actual-observed return of the security minus the actual return of the S\&P500 Banks index. CARs are then computed for the event windows of $(-5,+5),(-3,+3),(-1$, $+1)$ and $(-1,0)$ days around the agreement date, coinciding with or preceding the announcement date. The statistical significance of CARs and ARs has been assessed using the Patell (1976) test. The results of this analysis, not reported due to the small number of listed firms engaged in M\&As of punished targets but available upon request, show that the target reaps value creation benefits that are quite larger than that of the acquirer. Acquirers reap positive ARs that vary from positive and marginally significant to insignificant at the traditional levels of significance. 
All in all, the findings in section 4.2 are consistent with and complement the results of the analysis in section 4.1. The section 4.1 results show that Class 1 and 2 actions provide new, valuerelevant information on punished banks' management inefficiency, thus making punished banks more attractive to prospective acquirers. It follows that, at least in theory, acquisition of these poorly managed (i.e., punished) banks would increase the likelihood that operating performance gains are achievable for the post-acquisition combined entity (Hernando et al., 2009; Pasiouras et al., 2011). The findings from the analysis in section 4.2 are in line with this "acquire to restructure" theory: acquiring banks absorb the punished target banks and, as a result, are able to improve the management of the acquired assets within the combined entity by transferring and applying their superior managerial skills, thus restoring or maximizing the acquired assets' value (e.g., Hannan and Pilloff, 2009; Beccalli and Frantz, 2013; Caiazza et al., 2012).

\section{Conclusions}

We assess the "inefficient management" hypothesis of bank M\&As from a different and novel angle. Considering that financial safety problems and internal organization/governance weaknesses are traced to and caused by the poor quality of management decisions and practices, we contemplate that formal enforcement actions seeking to address these deficiencies manifest and communicate to the market new value-relevant information on punished banks' management quality/inefficiency. We build on this premise and construct a dataset of formal enforcement actions that signal supervisors' assessments of punished banks' management inefficiency. Class 1 enforcement actions include actions undertaken for financial safety and soundness reasons (e.g., capital adequacy and liquidity, asset quality, provisions and reserves, large exposures and exposures to related parties); Class 2 enforcement actions comprise actions undertaken for weaknesses relating to banks' internal organization/governance (e.g., internal control and audit systems, risk management systems, as well as money laundering and foreign assets control). 
We then assess in our baseline analysis whether Class 1 and 2 actions affect - above and beyond the already observable information on banks' characteristics and financial conditions - the probability that punished banks become targets of M\&As. We find that Class 1 and 2 enforcement actions increase the probability of punished banks' acquisition by $0.7 \%$ and by (up to) as much as $2 \%$ and $1.6 \%$ when the acquirer or the target, respectively, belongs to a BHC group. We also infer that Class 1 and 2 enforcement actions constitute the fourth most influential factor driving bank acquisitions, following the other determinants - namely, leverage (equity to assets), profitability (operating cash flow) and liquidity (liquidity ratio) - that have been identified by the literature to date as "conventional instigators" of bank M\&As. We obtain a similar picture for the period during the recent financial crisis: the likelihood of punished banks being acquired following the imposition of Class 1 and 2 actions remains unchanged compared to the pre-crisis period. Furthermore, we find that any improvement/deterioration in the punished bank's financial characteristics does not eliminate the predictive power of the Punished with Class 1/2 Enforcement Action dummy.

Considering that financial safety problems and internal control weaknesses constitute the outcome or revelation of bank management's poor capability, judgment and integrity, our baseline results confirm that Class 1 and 2 formal enforcement actions reflect and communicate to the market new, unobservable, value-relevant information on punished banks' management inefficiency, increasing the odds that a bid will be launched against such banks. In summary, therefore, the results of our analysis concerning the likelihood of acquisition of punished banks are in line with the "inefficient management" hypothesis.

We further extend our study to examine whether the acquisition of punished banks generates value in the form of an improved operating performance for the combined entity. We find that the acquisition of punished banks with Class 1 and 2 formal enforcement actions improves the operating performance of the post-acquisition combined entity not only compared to that resulting from the acquisition of non-punished banks but also compared to that of similar banks 
not engaged in M\&As during our sample period. Essentially, this finding lends support to the hypothesis that punished banks are less efficient banks and are more likely to be targets in M\&As because acquirers recognize an opportunity to transplant their superior managerial skills to restore and maximize the value of the acquired assets.

Our findings can be related to broader policy perspectives. In particular, our analysis reveals one of the channels through which the intended disciplinary effect of public enforcement is achieved in the banking field, that is, by increasing the likelihood of deviant banks being acquired. Moreover, our analysis indicates that, compared to the FDIC-assisted resolution mechanism of failed banks, which entails considerable costs - as documented by Granja et at. (2017) - private-led M\&As of punished but not yet failed banks constitutes a rather efficient “quasi-resolution” mechanism. 


\section{References}

Abadie, A. and G.W. Imbens, 2006. Large sample properties of matching estimators for average treatment effects. Econometrica: 74 (1), 235-267.

Adams, R. 2012. Consolidation and merger activity in the United States banking industry from 2000 through 2010. Federal Reserve Board Finance and Economic Discussion Working Paper 2012-51.

Amel, D., Barnes, C., Panetta, F. and C. Salleo. 2004. Consolidation and efficiency in the financial sector: A review of the international evidence. Journal of Banking and Finance: 28(10), 2493-2519.

Amel-Zadeh, A. and Y. Zhang. 2015. The economic consequences of financial restatements: Evidence from the market for corporate control. The Accounting Review: 90 (1), 129.

Athey, S., and G. W. Imbens. 2006. Identification and inference in nonlinear difference in differences models. Econometrica: 74(2), 431-497.

Beccalli, E. and P. Frantz. 2013. The determinants of mergers and acquisitions in banking. Journal of Financial Services Research: 43(3), 265-291.

Becht, M., Bolton, P. and A. Röell. 2011. Why bank governance is different. Oxford Review of Economic Policy: 27 (3), 437-463.

Beltratti, A. and G. Paladino. 2013. Is M\&A different during a crisis? Evidence from the European banking sector. Journal of Banking and Finance: 37(12), 5394-5405.

Berger, A. N. and S. M. Davies. 1998. The information content of bank examinations. Journal of Financial Services Research: 14(2), 117-144.

Berger, A. N., Demsetz, R. S. and P. E. Strahan. 1999. The consolidation of the financial services industry: Causes, consequences, and implications for the future. Journal of Banking and Finance: 23 (2-4), 135-194. 
Bliss, R. 2004. Market discipline: players, processes, and purposes. In: Market Discipline Across Countries and Industries. C. Borio, W. Hunter, G. Kaufman and K. Tsatsaronis (eds.). (MIT Press, 2004), 37-53.

Board of Governors of the Federal Reserve System (Fed). 2018 (Supplement 48). Commercial Bank Examination Manual.

Brunmeier J. and N. Willardson. September 2006. Supervisory enforcement actions since FIRREA and FDICIA. The Region (Federal Reserve Bank of Minneapolis Banking and Policy Issues Magazine): 22-27

Caiazza, S., Clare, A. and A. F. Pozzolo. 2012. What do bank acquirers want? Evidence from worldwide M\&A targets. Journal of Banking and Finance: 36 (9), 2641-2659.

Caiazza, S., Cotugno, M., Fiordelisi, F. and V. Stefanelli. 2018. The spillover effect of enforcement actions on bank risk-taking. Journal of Banking and Finance: 91, 146-159.

Caprio, G and R. Levine. 2002. Corporate governance in finance: concepts and international observations. In: Financial Sector Governance: The Roles of the Public and Private. R. E. Litan, M. Pomerleano, V. Sundararajan (eds). (Brookings Institution Press, 2002), 17-49.

Cornett, M. M., McNutt, J. J. and H. Tehranian. 2006. Performance changes around bank mergers: Revenue enhancements versus cost reductions. Journal of Money, Credit and Banking: 38 (4), 1013-1050.

Curry, T. 1997. "Bank examination and enforcement”. In: History of the Eighties - Lessons for the Future: An Examination of the Banking Crises of the 1980s and Early 1990s, Volume I. FDIC, 421-475.

Danisewicz, P., McGowan, D., Onali, E. and K. Schaeck. 2018. The real effects of banking supervision: evidence from enforcement actions. Journal of Financial Intermediation: 35 (Part A), 86-101.

de Haan, J and R. Vlahu. 2016. Corporate governance of banks: a survey. Journal of Economic Surveys: 30 (2), 228-277. 
Delis, M.D., Staikouras, P. K. and C. Tsoumas. 2017. Formal enforcement actions and bank behavior. Management Science: 63 (4), 959-987.

Deloitte Center for Financial Services (Deloitte \& Touche LLP). 2015. Enforcement actions in the banking industry: Trends and lessons learned. Deloitte University Press

DeLong, G. L. 2001. Stockholder gains from focusing versus diversifying bank mergers. Journal of Financial Economics: 59 (2), 221-252.

DeLong, G., and R. DeYoung. 2007. Learning by observing: Information spillovers in the execution and valuation of commercial bank M\&As. Journal of Finance: 62 (1), 181-216.

Devriese, J, Dewatripont, M., Heremans, D. and G. Nguyen. 2004. Corporate governance, regulation and supervision of banks. Financial Stability Review: 2 (1), 95-120.

DeYoung, R., Evanoff, D. D. and P. Molyneux. 2009. Mergers and acquisitions of financial institutions: A review of the post-2000 literature. Journal of Financial Services Research: 36 (23), 87-110.

DeYoung, R., Flannery, M. J., Lang, W. W. and S. M. Sorescu. 2001. The information content of bank exam ratings and subordinated debt prices. Journal of Money, Credit and Banking: 33 (4), 900-925.

Dunn, J., Intintoli, V. J. and J. J. McNutt. 2015. An examination of non-governmentassisted US commercial bank mergers during the financial crisis. Journal of Economics and Business: 77, 16-41.

Federal Deposit Insurance Corporation (FDIC). 2018. Risk Management Manual of Examination Policies.

Financial Stability Board (FSB). 2018. Strengthening Governance Frameworks to Mitigate Misconduct Risk: A Toolkit for Firms and Supervisors.

Flannery, M. J. and J. Houston. 1999. The value of a government monitor for U.S. banking firms. Journal of Money, Credit and Banking: 31 (1), 14-34. 
Focarelli, D., Panetta, F. and C. Salleo. 2002. Why do banks merge?. Journal of Money, Credit and Banking: 34 (4), 1047-1066.

General Accounting Office (GAO). 1993. Bank Examination Quality: FDIC Examinations Do Not Fully Assess Bank Safety and Soundness (GAO/AFMD-93-12).

General Accounting Office (GAO). 1993. Bank Examination Quality: FRB Examinations Do Not Fully Assess Bank Safety and Soundness (GAO/AFMD-93-13).

General Accounting Office (GAO). 1993. Bank Examination Quality: OCC Examinations Do Not Fully Assess Bank Safety and Soundness (GAO/AFMD-93-14).

General Accounting Office (GAO). 2015. Bank Regulation: Lessons Learned and a Framework for Monitoring Emerging Risks and Regulatory Response (GAO-15-365).

Gilbert, R. A. 1993. Implications of annual examinations for the bank insurance fund. Federal Reserve Bank of St. Louis Review: 75 (1), 35-52.

Goergen, M., O'Sullivan, N., and G. Wood. 2011. Private equity takeovers and employment in the UK: Some empirical evidence. Corporate Governance: An International Review: 19 (3), 259-275.

Gourieroux, C., Monfort, A., Renault, E. and A. Trognon. 1987. Generalised residuals. Journal of Econometrics: 34(1-2), 5-32.

Granja, J., Matvos G. and A. Seru. 2017. Selling failed banks. Journal of Finance: 72 (4), $1723-1784$.

Group of Thirty (G30). 2018. Banking Conduct and Culture: A Call for Sustained and Comprehensive Reform.

Hannan, T. H. and S. A. Roades. 1987. Acquisition targets and motives: The case of the banking industry. The Review of Economics and Statistics: 69 (1), 67-74.

Hannan, T. H. and S. J. Pilloff. 2009. Acquisition targets and motives in the banking industry. Journal of Money, Credit and Banking: 41 (6), 1167-1187. 
Hardies, K., Breesch, D. and J. Branson. 2016. Do (fe)male auditors impair audit quality? Evidence from going-concern opinions. European Accounting Review: 25 (1), 7-34.

Hernando, I., Nieto, M. J. and L. D. Wall. 2009. Determinants of domestic and cross-border bank acquisitions in the European Union. Journal of Banking and Finance: 33 (6), 1022-1032.

Herring, R. and A. Santomero. 2000. What is optimal financial regulation? In: The New Financial Architecture: Banking Regulation in the $21^{\text {st }}$ Century. B. Gup (ed.). (Quorum Books, 2000), 51-84.

Hirtle, B. J. and K. J. Stiroh. 2007. The return to retail and the performance of US banks. Journal of Banking and Finance: 31 (4), 1101-1133.

Ittonen, K., Vähämaa, E. and S. Vähämaa. 2013. Female auditors and accruals quality. Accounting Horizons: 27 (2), 205-228.

Jones, K. D. and T. Critchfield. 2005. Consolidation in the U.S. banking industry: Is the “long, strange trip" about to end?. FDIC Banking Review: 17(4), 31-61.

Jordan, J. S., Peek, J. and E. S. Rosengren. 2000. The market reaction to the disclosure for supervisory actions: Implications for bank transparency. Journal of Financial Intermediation: 9 (3), 298-319.

Khlif, H., and I. Achek. 2017. Gender in accounting research: A review. Managerial Auditing Journal: 32 (6), 627-655.

Kjellman, A., Tainio, R. and T. Kangas. 2014. Bank management in bank decline: Bank mergers as a recovery recipe?. Journal of Economic and Financial Studies: 2 (6), 26-36.

Koetter, M., Bos, J. W., Heid, F., Kolari, J. W., Kool, C. J. and D. Porath. 2007. Accounting for distress in bank mergers. Journal of Banking and Finance: 31 (10), 3200-3217.

Lehn, K. M. and M. Zhao. 2006. CEO turnover after acquisitions: Are bad bidders fired? Journal of Finance: 61 (4), 1759-1811.

Levine, R. 2004. The corporate governance of banks: a concise discussion of concepts and evidence. World Bank Policy Research Working Paper No 3404. 
Marquardt, C. and E. Zur. 2015. The role of accounting quality in the M\&A market. Management Science: 61 (13), 604-623.

Martin, X. and R. Shalev. 2017. Target firm-specific information and acquisition efficiency. Management Science: 63 (30), 672-690.

Mehran, H., Morrison, A. and J. Sapiro. 2011. Corporate governance and banks: what have we learned from the financial crisis?. Federal Reserve Bank of New York Staff Report No 502.

Milne, A.. 2002. Bank capital regulation as an incentive mechanism: Implications for portfolio choice. Journal of Banking and Finance: 26 (1), 1-23.

Minetti, R., and S. C. Zhu. 2011. Credit constraints and firm export: Microeconomic evidence from Italy. Journal of International Economics: 83 (2), 109-125.

Mitchell, M. L., and K. Lehn. 1990. Do bad bidders become good targets?. Journal of Political Economy: 98 (2), 372-398.

Mullineaux, A. 2006. The corporate governance of banks. Journal of Financial Regulation and Compliance: 14 (4), 375-382.

Nguyen, D. D., Hagendorff, J. and A. Eshraghi. 2016. Can bank boards prevent misconduct? Review of Finance: 20 (1), 1-36.

O’Donnell, E. and E. N. Johnson. 2001. The effects of auditor gender and task complexity on information processing efficiency. International Journal of Auditing: 5 (2), 91-105.

O’Keefe, J. P.. 1996. Banking industry consolidation: Financial attributes of merging banks. FDIC Bank Review: 9 (1), 18.

Offenberg, D.. 2009. Firm size and the effectiveness of the market for corporate control. Journal of Corporate Finance: 15 (1), 66-79.

Offenberg, D., Straska, M. and H. G. Waller. 2014. Who gains from buying bad bidders?. Journal of Financial and Quantitative Analysis: 49 (2), 513-540.

Office of the Comptroller of the Currency (OCC). 2018. Policies and Procedures Manual: Bank Enforcement Actions and Related Matters. 
Pasiouras, F., Tanna, S. and C. Gaganis. 2011. What drives acquisitions in the EU banking industry? The role of bank regulation and supervision framework, bank specific and market specific factors. Financial Markets, Institutions \& Instruments: 20 (2), 29-77.

Pasiouras, F., Tanna, S. and C. Zopounidis. 2007. The identification of acquisition targets in the EU banking industry: An application of multicriteria approaches. International Review of Financial Analysis: 16 (30), 262-281.

Patell, J.M.. 1976. Corporate forecasts of earnings per share and stock price behavior: Empirical test. Journal of Accounting Research: 14 (2), 246-276.

Peek, J. and E. Rosengren. 1995. Bank regulatory agreements in New England. New England Economic Review: May-June, 15-24.

Peek, J. and E. Rosengren. 1996. Bank regulatory agreements and real estate lending. Real Estate Economics: 24 (1), 55-73.

Peek, J., Rosengren, E. S. and G. M. Tootell. 1998. Does the Federal Reserve have an informational advantage? You can bank on it. Federal Reserve Bank of Boston Research Department Working Paper No. 98-2.

Seballos, L. D. and J. B. Thomson. 1990. Underlying causes of commercial bank failures in the 1980s. Federal Reserve Bank of Cleveland Economic Commentary.

Stiebale, J.. 2016. Cross-border M\&As and innovative activity of acquiring and target firms. Journal of International Economics: 99, 1-15.

Wang, C., and F. Xie. 2009. Corporate governance transfer and synergistic gains from mergers and acquisitions. The Review of Financial Studies: 22 (2), 829-858.

Wheelock, D. C., and P. W. Wilson. 2000. Why do banks disappear? The determinants of US bank failures and acquisitions. Review of Economics and Statistics: 82 (1), 127-138. 
Table I - Enforcement Actions of Class 1 and 2 and Bank M\&As by Year

The table reports the number of Class 1 and 2 formal enforcement actions (Panel A) and the number of bank M\&As (Panel B) in the first working sample by year for the period 2000-2014 (for details, see the main text). The Punished with Class 1/2 Enforcement Action dummy variable equals 1 for the eight subsequent quarters after the quarter during which an enforcement action of Class 1 or 2 imposed on a bank becomes effective and 0 otherwise. Thus, the yearly figures of the Punished with Class 1/2 Enforcement Action dummy variable represent the punished bank-quarters when the relevant Class 1 or 2 enforcement action has been imposed on the punished entity either in a quarter of the current year, except for the last quarter of the year; in a quarter of the previous year; or in a quarter of the year before that.

\begin{tabular}{|c|c|c|c|c|c|c|}
\hline \multirow{3}{*}{ Year } & \multicolumn{4}{|c|}{ Panel A } & \multicolumn{2}{|r|}{ Panel B } \\
\hline & \multicolumn{3}{|c|}{ Enforcement Actions } & \multirow{2}{*}{$\begin{array}{l}\text { Punished with Class } \\
\text { 1/2 Enforcement } \\
\text { Action dummy } \\
\text { variable }\end{array}$} & \multirow{2}{*}{ Bank M\&As } & \multirow{2}{*}{$\begin{array}{l}\text { M\&As involving a target bank for } \\
\text { which the Punished with Class } \\
\text { 1/2 Enforcement Action dummy } \\
\text { variable equals } 1 \text { at the quarter the } \\
\text { deal becomes effective }\end{array}$} \\
\hline & Class 1 & Class 2 & Class $1 / 2$ & & & \\
\hline 2000 & 51 & 17 & 68 & 93 & 164 & 1 \\
\hline 2001 & 68 & 22 & 90 & 347 & 133 & 6 \\
\hline 2002 & 89 & 25 & 114 & 614 & 111 & 7 \\
\hline 2003 & 68 & 32 & 100 & 740 & 152 & 11 \\
\hline 2004 & 70 & 27 & 97 & 695 & 152 & 19 \\
\hline 2005 & 39 & 27 & 66 & 634 & 146 & 10 \\
\hline 2006 & 42 & 26 & 68 & 506 & 179 & 12 \\
\hline 2007 & 48 & 31 & 79 & 453 & 159 & 8 \\
\hline 2008 & 161 & 41 & 202 & 620 & 114 & 9 \\
\hline 2009 & 463 & 42 & 505 & 1,287 & 61 & 10 \\
\hline 2010 & 600 & 41 & 641 & 2,622 & 74 & 20 \\
\hline 2011 & 253 & 47 & 300 & 3,250 & 91 & 25 \\
\hline 2012 & 199 & 43 & 242 & 2,394 & 165 & 33 \\
\hline 2013 & 64 & 44 & 108 & 1,441 & 179 & 29 \\
\hline 2014 & 49 & 37 & 86 & 842 & 137 & 10 \\
\hline Total & 2,264 & 502 & 2,766 & $\mathbf{1 6 , 5 3 8}$ & 2,017 & 210 \\
\hline
\end{tabular}


Table II - Summary Statistics

\section{Part I: Sample for the Acquisition Likelihood of Punished Banks (Hypothesis I)}

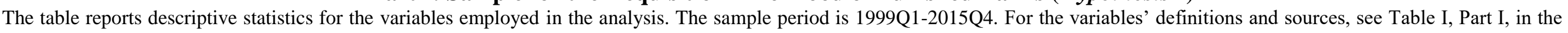

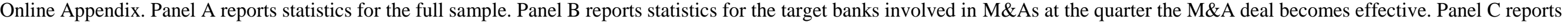
descriptive statistics for these target banks for which the Punished with Class 1/2 Enforcement Action dummy takes the value of 1.

\begin{tabular}{|c|c|c|c|c|c|c|c|c|c|c|c|c|c|c|c|}
\hline \multirow[b]{2}{*}{ Variable } & \multicolumn{5}{|c|}{ Panel A. Full Sample } & \multicolumn{5}{|c|}{ Panel B. Targets involved in M\&As } & \multicolumn{5}{|c|}{$\begin{array}{l}\text { Panel C. Targets punished with Class 1/2 } \\
\text { Enforcement Action }\end{array}$} \\
\hline & Obs. & Mean & St. Dev. & Min. & Max. & Obs. & Mean & St. Dev. & Min. & Max. & Obs. & Mean & St. Dev. & Min. & Max. \\
\hline Equity to Assets Ratio & 520,543 & 0.110 & 0.044 & -0.234 & 0.517 & 1,988 & 0.108 & 0.049 & -0.234 & 0.500 & 209 & 0.096 & 0.051 & 0.008 & 0.462 \\
\hline Risk-Weighted Assets Ratio & 521,251 & 0.672 & 0.137 & 0.218 & 1.105 & 1,986 & 0.663 & 0.146 & 0.225 & 1.080 & 208 & 0.654 & 0.119 & 0.306 & 1.011 \\
\hline OPCFROA & 524,519 & 0.008 & 0.031 & -2.308 & 2.360 & 2,011 & 0.006 & 0.062 & -0.529 & 1.987 & 209 & -0.008 & 0.023 & -0.133 & 0.050 \\
\hline ROA & 524,313 & 0.007 & 0.013 & -0.303 & 0.318 & 2,013 & 0.004 & 0.021 & -0.166 & 0.303 & 210 & -0.007 & 0.020 & -0.116 & 0.049 \\
\hline$\sigma(\mathrm{ROA})$ & 495,911 & 0.006 & 0.009 & 0 & 0.375 & 1,932 & 0.007 & 0.012 & 0.001 & 0.290 & 195 & 0.010 & 0.008 & 0.002 & 0.051 \\
\hline Non-Performing Loans Ratio & 512,368 & 0.010 & 0.014 & 0 & 0.083 & 1,903 & 0.012 & 0.016 & 0 & 0.080 & 168 & 0.026 & 0.023 & 0 & 0.080 \\
\hline Non-Interest Income Ratio & 524,442 & 0.122 & 0.117 & -1.190 & 1.351 & 2,007 & 0.123 & 0.136 & -1.109 & 1 & 207 & 0.118 & 0.128 & -0.537 & 0.791 \\
\hline Inefficiency & 524,180 & 0.731 & 0.472 & -12.756 & 14.357 & 2,011 & 0.844 & 0.586 & -7.453 & 12.035 & 208 & 1.113 & 1.098 & -7.453 & 10.776 \\
\hline Net Interest Margin & 521,346 & 0.040 & 0.091 & -3.671 & 7.333 & 1,982 & 0.051 & 0.241 & -0.002 & 6.770 & 208 & 0.049 & 0.190 & -0.002 & 2.752 \\
\hline Liquidity Ratio & 522,429 & 0.067 & 0.066 & -0.002 & 0.513 & 1,995 & 0.083 & 0.085 & 0 & 0.492 & 207 & 0.106 & 0.092 & 0.004 & 0.472 \\
\hline Loans to Assets Ratio & 525,382 & 0.626 & 0.167 & 0 & 1.207 & 2,017 & 0.611 & 0.188 & 0 & 1.020 & 210 & 0.617 & 0.149 & 0 & 0.889 \\
\hline Size & 525,384 & 11.846 & 1.373 & 0 & 21.463 & 2,017 & 11.932 & 1.537 & 4.190 & 20.050 & 210 & 11.782 & 1.669 & 8.679 & 20.050 \\
\hline Market Share & 523,815 & 0.341 & 0.136 & 0.077 & 1 & 2,008 & 0.324 & 0.125 & 0.110 & 1 & 210 & 0.332 & 0.154 & 0.141 & 1 \\
\hline Multi-state dummy & 521,924 & 0.055 & 0.228 & 0 & 1 & 2,001 & 0.056 & 0.230 & 0 & 1 & 208 & 0.091 & 0.289 & 0 & 1 \\
\hline Bank Age & 525,308 & 3.848 & 1.113 & 0 & 5.447 & 2,013 & 3.603 & 1.076 & 0 & 5.288 & 210 & 3.658 & 1.076 & 1.099 & 5.288 \\
\hline
\end{tabular}


Part II: Sample for the Operating Performance in Acquisition Deals With Punished Banks as Targets (Hypothesis II)

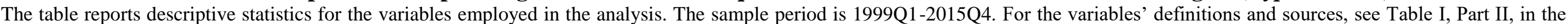

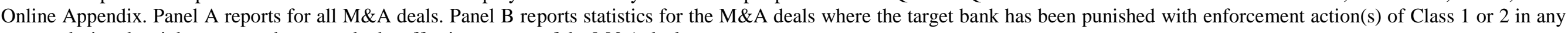
quarter during the eight quarters that precede the effective quarter of the M\&A deal.

\begin{tabular}{|c|c|c|c|c|c|c|c|c|c|c|}
\hline \multirow[b]{2}{*}{ Variable } & \multicolumn{5}{|c|}{ Panel A: All M\&A Deals } & \multicolumn{5}{|c|}{$\begin{array}{c}\text { Panel B: M\&A Deals with Punished with Class 1/2 } \\
\text { Enforcement Action Targets }\end{array}$} \\
\hline & Obs. & Mean & St. Dev. & Min. & Max. & Obs. & Mean & St. Dev. & Min. & Max. \\
\hline Change in Industry-Size-Adjusted ROA - $(-1,+1)$ years & 752 & $3.9 \mathrm{E}-04$ & 0.011 & -0.094 & 0.112 & 92 & 0.003 & 0.015 & -0.030 & 0.112 \\
\hline Change in Industry-Size-Adjusted ROA - $(-1,+2)$ years & 683 & $-3.6 \mathrm{E}-04$ & 0.012 & -0.097 & 0.112 & 82 & 0.003 & 0.016 & -0.052 & 0.112 \\
\hline Change in Industry-Size-Adjusted OPCFROA - $(-1,+1)$ years & 752 & $3.2 \mathrm{E}-04$ & 0.013 & -0.094 & 0.120 & 92 & 0.004 & 0.016 & -0.029 & 0.120 \\
\hline Change in Industry-Size-Adjusted OPCFROA $-(-1,+2)$ years & 683 & $-3.7 \mathrm{E}-04$ & 0.013 & -0.099 & 0.120 & 82 & 0.004 & 0.018 & -0.056 & 0.120 \\
\hline Relative Size & 752 & 0.336 & 0.448 & 0.011 & 6.879 & 92 & 0.340 & 0.716 & 0.013 & 6.587 \\
\hline Acquirer's Total Assets & 752 & 12.981 & 1.355 & 9.368 & 18.383 & 92 & 12.946 & 1.249 & 9.556 & 17.898 \\
\hline Change in Equity to Assets Ratio & 752 & 0.002 & 0.022 & -0.111 & 0.175 & 92 & 0.001 & 0.018 & -0.046 & 0.063 \\
\hline Change in Subordinated Debt to Assets Ratio & 752 & $2.1 \mathrm{E}-04$ & 0.003 & -0.019 & 0.031 & 92 & -0.001 & 0.003 & -0.016 & 0.010 \\
\hline Private Equity Dummy & 752 & 0.033 & 0.179 & 0.000 & 1.000 & 92 & 0.033 & 0.179 & 0.000 & 1.000 \\
\hline In-State Buyer Dummy & 752 & 0.815 & 0.388 & 0.000 & 1.000 & 92 & 0.826 & 0.381 & 0.000 & 1.000 \\
\hline Geographic Market Expansion & 752 & 1.691 & 0.673 & 1.000 & 3.000 & 92 & 1.696 & 0.707 & 1.000 & 3.000 \\
\hline Branch Ratio & 752 & 0.402 & 0.428 & 0.006 & 4.000 & 92 & 0.389 & 0.379 & 0.014 & 2.000 \\
\hline
\end{tabular}


Table III - Enforcement Actions and Acquisition Likelihood: Baseline Results

The table reports marginal effects and z-statistics (in parentheses) of equation (1) estimated with robust standard errors clustered by bank. The dependent variable Target is a dummy variable that equals 1 for the target bank-quarter during which an M\&A deal (not involving a failed and ceased to exist bank as target) becomes effective and 0 otherwise. Only M\&A cases where there is a change in control are considered. The Punished with Class 1/2 Enforcement Action is a dummy variable that equals 1 for the eight subsequent quarters after the quarter during which a Class 1 or 2 enforcement action imposed on a bank becomes effective and 0 otherwise. Two different models are employed, the "Literature" model and the "Enhanced" model reported in Panels A and B, respectively, the second being enhanced with variables proxying for the CAMELS rating of a bank. All explanatory variables, except for the Punished with Class 1/2 Enforcement Action, are lagged either eight quarters or four quarters.

A full set of time dummies is included in all regressions. For the variables' definitions and sources, see Table I, Part I, in the Online Appendix. The sample period is 1999Q1-2015Q4. The ***,**, and * marks denote statistical significance at the 1, 5, and 10\% level, respectively.

Panel A: Literature Model

Panel B: Enhanced Model

\begin{tabular}{|c|c|c|c|c|c|c|c|c|}
\hline \multirow[b]{2}{*}{ Punished with Class 1/2 Enforcement Action } & \multicolumn{2}{|c|}{$\begin{array}{c}\text { Control variables lagged } \\
\text { eight quarters }\end{array}$} & \multicolumn{2}{|c|}{$\begin{array}{l}\text { Control variables lagged } \\
\text { four quarters }\end{array}$} & \multicolumn{2}{|c|}{$\begin{array}{c}\text { Control variables lagged } \\
\text { eight quarters }\end{array}$} & \multicolumn{2}{|c|}{$\begin{array}{l}\text { Control variables lagged } \\
\text { four quarters }\end{array}$} \\
\hline & $0.007 * * *$ & $(7.90)$ & $0.007 * * *$ & $(7.50)$ & $0.007 * * *$ & $(7.01)$ & $0.007 * * *$ & $(6.25)$ \\
\hline Equity to Assets Ratio & $-0.018 * * *$ & $(-5.60)$ & $-0.022 * * *$ & $(-7.31)$ & & & & \\
\hline Risk-Based Capital Ratio & & & & & $-0.007 * * *$ & $(-3.05)$ & $-0.006 * * *$ & $(-2.72)$ \\
\hline Risk-Weighted Assets Ratio & & & & & -0.002 & $(-1.20)$ & $-0.003^{* *}$ & $(-1.98)$ \\
\hline Operating Cash Flow & $-0.016^{* *}$ & $(-1.97)$ & $-0.021 * *$ & $(-2.56)$ & 0.0001 & $(0.01)$ & -0.013 & $(-0.57)$ \\
\hline$\sigma($ Operating Cash Flow $)$ & & & & & 0.003 & $(0.27)$ & -0.004 & $(-0.23)$ \\
\hline Non-Performing Loans Ratio & & & & & $0.017 * *$ & $(2.08)$ & $0.016^{* *}$ & $(2.00)$ \\
\hline Non-Interest Income Ratio & & & & & $-0.002 *$ & $(-1.95)$ & $-0.002 * *$ & $(-2.27)$ \\
\hline Inefficiency & $0.001 * * *$ & $(3.55)$ & $0.001 * * *$ & $(4.88)$ & $0.002 * * *$ & $(7.18)$ & $0.002 * * *$ & $(7.27)$ \\
\hline Net Interest Margin & 0.001 & $(0.91)$ & $0.002 * *$ & $(2.51)$ & -0.0004 & $(-0.09)$ & $0.003 * * *$ & $(3.98)$ \\
\hline Liquidity Ratio & $0.008 * * *$ & $(5.26)$ & $0.009 * * *$ & $(6.08)$ & $0.009 * * *$ & $(5.63)$ & $0.009 * * *$ & $(5.85)$ \\
\hline Loans to Assets Ratio & -0.001 & $(-1.24)$ & -0.001 & $(-1.30)$ & -0.002 & $(-1.33)$ & -0.001 & $(-1.00)$ \\
\hline Deposits to Assets Ratio & $-0.003 * *$ & $(-2.31)$ & $-0.002 *$ & $(-1.79)$ & $-0.004 * * *$ & $(-2.79)$ & $-0.003 * *$ & $(-2.07)$ \\
\hline Size & $0.0003 * * *$ & $(2.64)$ & $0.0003 * * *$ & $(3.19)$ & $0.0003^{* *}$ & $(2.38)$ & $0.0004 * * *$ & $(3.48)$ \\
\hline Market Share & $-0.002 * * *$ & $(-2.63)$ & $-0.003 * * *$ & $(-3.19)$ & $-0.003 * * *$ & $(-2.92)$ & $-0.002 * * *$ & $(-2.97)$ \\
\hline Multi-state Dummy & -0.001 & $(-1.33)$ & -0.001 & $(-1.58)$ & -0.001 & $(-1.56)$ & $-0.001 *$ & $(-1.79)$ \\
\hline Bank Age & $-0.001 * * *$ & $(-11.12)$ & $-0.001 * * *$ & $(-9.74)$ & $-0.002 * * *$ & $(-12.57)$ & $-0.001 * * *$ & $(-12.51)$ \\
\hline Time Fixed Effects & \multicolumn{2}{|c|}{ Yes } & \multicolumn{2}{|c|}{ Yes } & \multicolumn{2}{|c|}{ Yes } & \multicolumn{2}{|c|}{ Yes } \\
\hline Pseudo R-squared & \multicolumn{2}{|c|}{0.030} & \multicolumn{2}{|c|}{0.030} & \multicolumn{2}{|c|}{0.036} & \multicolumn{2}{|c|}{0.035} \\
\hline Number of Banks & \multicolumn{2}{|c|}{10,364} & \multicolumn{2}{|c|}{10,901} & \multicolumn{2}{|c|}{9,582} & \multicolumn{2}{|c|}{10,116} \\
\hline Observations & \multicolumn{2}{|c|}{396,069} & \multicolumn{2}{|c|}{438,553} & \multicolumn{2}{|c|}{371,280} & \multicolumn{2}{|c|}{409,029} \\
\hline
\end{tabular}




\section{Table IV - Enforcement Actions and Acquisition Likelihood - Alternative Econometric Specifications}

The table reports results from three alternative econometric specifications. The first column reports coefficient estimates and t-statistics (in parentheses) from a fixed effects OLS model as presented in equation (1) with robust standard errors clustered by bank. The second and the third column report results from two IV econometric techniques (equations (2) and (3) results in the lower and upper part of the table, respectively) where the endogenous variable is the Punished with Class 1/2 Enforcement Action. In the second column are reported the results (coefficient estimates) from a treatment effects model, whereas in the third column are reported the results (marginal effect of the Punished with Class $1 / 2$ Enforcement Action) from a recursive bivariate probit model. The treatment effects model is estimated with the two-step consistent estimator, whereas the recursive bivariate probit is estimated with maximum likelihood and robust standard errors clustered by bank. In all three specifications the dependent variable Target is a dummy variable that equals 1 for the target bank-quarter during which an M\&A deal (not involving a failed and ceased to exist bank as target) becomes effective and 0 otherwise. Only M\&A cases where there is a change in control are considered. The Punished with Class 1/2 Enforcement Action is a dummy variable that equals 1 for the eight subsequent quarters after the quarter during which a Class 1 or 2 enforcement action imposed on a bank becomes effective and 0 otherwise. The "Literature" model is employed in all three specifications with control variables lagged four quarters. For brevity, only the coefficients of interest are reported. In the first stage probit of the treatment effects model and the recursive bivariate probit model (equation (2)) we use a set of proxies of the CAMELS ratings' components that affect the likelihood of punishment of bank and the gender of the supervisor bank examiners as instrument, all lagged four quarters. For more information about the construction of the instrument see the main text. Due to data availability reasons for the instrument, only FDIC and OCC supervised banks enter the analysis. For the variables' definitions and sources, see Table I, Part I, in the Online Appendix. The sample period is 1999Q1-2015Q4. The ***,**, and $*$ marks denote statistical significance at the 1,5 and $10 \%$ level, respectively.

\begin{tabular}{|c|c|c|c|c|c|}
\hline \multirow[b]{3}{*}{ Punished with Class $1 / 2$ Enforcement Action } & \multirow[t]{2}{*}{ Fixed Effects OLS } & \multicolumn{2}{|c|}{$\begin{array}{c}\text { Treatment Effects } \\
\text { Model }\end{array}$} & \multicolumn{2}{|c|}{$\begin{array}{c}\text { Recursive Bivariate } \\
\text { Probit Model }\end{array}$} \\
\hline & & \multicolumn{4}{|c|}{ Equation (3) results } \\
\hline & $0.007 * * *$ & $0.008 * * *$ & $(4.88)$ & $0.004 * * *$ & $(3.74)$ \\
\hline Control Variables Lagged Four Quarters & Yes & \multicolumn{2}{|c|}{ Yes } & \multicolumn{2}{|c|}{ Yes } \\
\hline Time Fixed Effects & Yes & \multicolumn{2}{|c|}{ Yes } & \multicolumn{2}{|c|}{ Yes } \\
\hline Adj. R-sq & 0.058 & \multicolumn{2}{|c|}{-} & \multicolumn{2}{|c|}{-} \\
\hline Number of Banks & 10,782 & \multicolumn{2}{|c|}{9,490} & \multicolumn{2}{|c|}{9,490} \\
\hline \multirow[t]{2}{*}{ Observations } & 469,544 & \multicolumn{2}{|c|}{381,162} & \multicolumn{2}{|c|}{381,162} \\
\hline & & \multicolumn{4}{|c|}{$\begin{array}{c}\text { Equation (2) results (Probit model): } \\
\text { Dependent Variable is Punished with Class } 1 / 2 \\
\text { Enforcement Action }\end{array}$} \\
\hline Gender of Supervisor's Bank Examiners (IV) & & $0.609 * * *$ & $(6.42)$ & $0.609 * * *$ & $(2.74)$ \\
\hline Risk-Based Capital Ratio & & $-2.556 * * *$ & $(-23.92)$ & $-2.555 * * *$ & $(-7.23)$ \\
\hline Risk-Weighted Assets Ratio & & $0.096^{*}$ & $(1.66)$ & 0.096 & $(0.62)$ \\
\hline ROA & & $-23.894 * * *$ & $(-46.89)$ & $-23.895 * * *$ & $(-14.95)$ \\
\hline$\sigma(\mathrm{ROA})$ & & $14.827 * * *$ & $(22.46)$ & $14.827 * * *$ & $(6.67)$ \\
\hline Liquidity Ratio & & $0.369 * * *$ & $(4.30)$ & $0.370 *$ & $(1.70)$ \\
\hline Non-Performing Loans Ratio & & $21.986 * * *$ & $(87.03)$ & $21.986 * * *$ & $(41.11)$ \\
\hline Non-Interest Income Ratio & & $0.331 * * *$ & $(7.25)$ & $0.331 * *$ & $(2.30)$ \\
\hline Trading Securities Ratio & & $-0.517 * * *$ & $(-10.88)$ & $-0.517 * * *$ & $(-4.00)$ \\
\hline FDIC Dummy & & $-0.532 * * *$ & $(-52.05)$ & $-0.532 * * *$ & $(-19.50)$ \\
\hline GDP growth (y-o-y) & & $-0.015 * * *$ & $(-4.37)$ & $-0.015 * * *$ & $(-3.22)$ \\
\hline Effective Funds Rate & & $-0.046 * * *$ & $(-15.13)$ & $-0.046 * * *$ & $(-6.44)$ \\
\hline Financial Stress Index & & $-0.012 * *$ & $(-2.18)$ & -0.012 & $(-1.50)$ \\
\hline Constant & & $-1.402 * * *$ & $(-24.75)$ & $-1.402 * * *$ & $(-8.60)$ \\
\hline Wald test of rho ( $\mathrm{p}$-value in parenthesis) & & & & 0.04 & $(0.84)$ \\
\hline Pseudo R-sq & \multicolumn{5}{|c|}{0.063} \\
\hline Observations & & \multicolumn{2}{|c|}{381,162} & \multicolumn{2}{|c|}{381,162} \\
\hline
\end{tabular}


Table V - Enforcement Actions and Acquisition Likelihood: Different Sub-sample Periods

The table reports marginal effects and z-statistics (in parentheses) of equation (1) estimated with robust standard errors clustered by bank for different sub-sample periods. The crisis era is the period 2007Q1-2009Q4; Excluding crisis era are the periods 1999Q1-2006Q4 and 2010Q1-2015Q4; Pre-crisis is the period 1999Q1-2006Q4; and Post-crisis is the period 2010Q12015Q4. The dependent variable Target is a dummy variable that equals 1 for the target bank-quarter during which an M\&A deal (not involving a failed and ceased to exist bank as target) becomes effective and 0 otherwise. Only M\&A cases where there is a change in control are considered. The Punished with Class 1/2 Enforcement Action is a dummy variable that equals 1 for the eight subsequent quarters after the quarter during which an enforcement action of Class 1 or 2 imposed on a bank becomes effective and 0 otherwise. The "Literature Model" is employed with control variables lagged four quarters. A full set of time dummies is included in all regressions. For brevity, only the coefficient of interest is reported. The ***, **, and * marks denote statistical significance at the 1,5 , and $10 \%$ level, respectively.

\begin{tabular}{|c|c|c|c|c|}
\hline & Crisis Era & $\begin{array}{l}\text { Excluding } \\
\text { Crisis Era }\end{array}$ & Pre-Crisis & Post-Crisis \\
\hline Punished with Class $1 / 2$ Enforcement Action & $0.007^{* * * *}$ & $0.007^{* * * *} \quad(6.56)$ & $0.012^{* * *}$ & $0.005^{* * *}$ \\
\hline Control Variables Lagged Four Quarters & Yes & Yes & Yes & Yes \\
\hline Time Fixed Effects & Yes & Yes & Yes & Yes \\
\hline Pseudo R-squared & 0.031 & 0.029 & 0.027 & 0.040 \\
\hline Number of Banks & 7,896 & 10,832 & 9,673 & 7,751 \\
\hline Observations & 87,200 & 323,694 & 224,717 & 126,636 \\
\hline
\end{tabular}

Testing the equality of the Punished with Class 1/2 Enforcement Action marginal effect across sub-sample periods

\begin{tabular}{lc}
\hline Crisis era vs Excluding crisis era & 0.14 \\
& $(0.70)$ \\
Crisis era vs Pre-crisis & 2.20 \\
& $(0.14)$ \\
Crisis era vs Post-crisis & 1.54 \\
& $(0.22)$ \\
Pre-crisis vs Post-crisis & $11.74 * * *$ \\
\hline \hline
\end{tabular}


Table VI: Performance Improvement in M\&As with Punished Targets: Cross-Sectional Analysis

The table reports coefficient estimates and t statistics (in parentheses) of equation (4) estimated with OLS and robust standard errors. Panel A reports the results when the dependent variables, reported in the first row of the table, is the $(-1,+1)$ year change of the operating performance measure employed around the year of the M\&A deal. Panel B reports the results when the relevant change is calculated in the $(-1,+2)$ year frame around the year of the M\&A deal. The Punished with Class $1 / 2$ Enforcement Action Target is a dummy variable that equals 1 if the target bank in an M\&A deal has been punished with a Class 1 or 2 enforcement action that has become effective in any of eight quarters preceding the M\&A deal, and 0 otherwise. A full set of year dummies is included in all regressions. For the variables' definitions and sources, see Table I, Part II, in the Online Appendix. The sample period is $1999-2015$. The $* * * * *$, and $*$ marks denote statistical significance at the 1,5 , and $10 \%$ level, respectively.

\begin{tabular}{|c|c|c|c|c|c|c|c|c|}
\hline \multirow[b]{3}{*}{ Punished with Class $1 / 2$ Enforcement Action Target } & \multicolumn{4}{|c|}{ Panel A: $(-1,+1)$ Year Change } & \multicolumn{4}{|c|}{ Panel B: $(-1,+2)$ Year Change } \\
\hline & \multicolumn{2}{|c|}{$\begin{array}{c}\text { Industry-Size-Adjusted } \\
\text { ROA }\end{array}$} & \multicolumn{2}{|c|}{$\begin{array}{c}\text { Industry-Size-Adjusted } \\
\text { OPCFROA }\end{array}$} & \multicolumn{2}{|c|}{$\begin{array}{c}\text { Industry-Size-Adjusted } \\
\text { ROA }\end{array}$} & \multicolumn{2}{|c|}{$\begin{array}{c}\text { Industry-Size-Adjusted } \\
\text { OPCFROA }\end{array}$} \\
\hline & $0.0034 * * *$ & $(2.68)$ & $0.0038 * * *$ & $(2.69)$ & $0.0042 * * *$ & $(2.90)$ & $0.0049 * * *$ & $(3.02)$ \\
\hline Relative Size & 0.0047 & $(1.21)$ & 0.0044 & $(1.00)$ & 0.0041 & $(1.03)$ & 0.0037 & $(0.84)$ \\
\hline Acquirer's Total Assets & $-0.0010 * *$ & $(-2.55)$ & $-0.0013 * * *$ & $(-2.94)$ & $-0.0017 * * *$ & $(-3.71)$ & $-0.0021 * * *$ & $(-4.11)$ \\
\hline Change in Equity to Assets Ratio & 0.0293 & $(0.78)$ & 0.0239 & $(0.60)$ & $0.0521 *$ & $(1.75)$ & $0.0554 *$ & $(1.77)$ \\
\hline Change in Subordinated Debt to Assets Ratio & 0.1857 & $(0.59)$ & 0.0003 & $(0.00)$ & -0.0572 & $(-0.19)$ & -0.1039 & $(-0.29)$ \\
\hline Private Equity Dummy & $0.0072 * *$ & $(2.08)$ & $0.0090 * *$ & $(2.19)$ & $0.0079 *$ & $(1.72)$ & $0.0092 *$ & $(1.75)$ \\
\hline In-State Buyer Dummy & $0.0023^{*}$ & $(1.77)$ & 0.0025 & $(1.63)$ & $0.0025^{*}$ & $(1.84)$ & $0.0030^{*}$ & $(1.86)$ \\
\hline Geographic Market Expansion & -0.0008 & $(-1.38)$ & -0.0008 & $(-1.12)$ & -0.0001 & $(-0.18)$ & -0.0001 & $(-0.13)$ \\
\hline Branch Ratio & $-0.0025^{*}$ & $(-1.68)$ & -0.0025 & $(-1.50)$ & $-0.0027 *$ & $(-1.74)$ & -0.0026 & $(-1.53)$ \\
\hline Constant & 0.0088 & $(1.39)$ & $0.0126 *$ & $(1.81)$ & $0.0171 * *$ & $(2.44)$ & $0.0215 * * *$ & $(2.80)$ \\
\hline Year Dummies & \multicolumn{2}{|c|}{ Yes } & \multicolumn{2}{|c|}{ Yes } & \multicolumn{2}{|c|}{ Yes } & \multicolumn{2}{|c|}{ Yes } \\
\hline Adj. R-squared & \multicolumn{2}{|c|}{0.100} & \multicolumn{2}{|c|}{0.093} & \multicolumn{2}{|c|}{0.111} & \multicolumn{2}{|c|}{0.112} \\
\hline No of Punished Targets Deals & \multicolumn{2}{|c|}{92} & \multicolumn{2}{|c|}{92} & \multicolumn{2}{|c|}{82} & \multicolumn{2}{|c|}{82} \\
\hline Observations & \multicolumn{2}{|c|}{752} & \multicolumn{2}{|c|}{752} & \multicolumn{2}{|c|}{683} & \multicolumn{2}{|c|}{683} \\
\hline
\end{tabular}




\section{Table VII. Performance Improvement in M\&As with Punished Targets: Propensity Score Matching}

The table reports coefficient estimates and t-statistics (in parentheses) from propensity score analysis. The Punished with Class 1/2 Enforcement Action Target is a dummy variable that equals 1 if the target bank in an M\&A deal has been punished with a Class 1 or 2 enforcement action that has become effective in any of eight quarters preceding the M\&A deal, and 0 otherwise. For the outcome variables' definitions and sources, see Table I, Part II, in the Online Appendix. The sample period is 1999-2015. The ***, **, and * marks denote statistical significance at the 1,5 , and $10 \%$ level, respectively.

\section{Panel A: Comparison Group is Banks Engaged in M\&As of Non-Punished Target Banks}

\begin{tabular}{|c|c|c|c|c|c|c|c|c|}
\hline \multirow{3}{*}{$\begin{array}{l}\text { ATT } \\
\text { Outcome variable: (Change in:) } \\
\text { Punished with Class } 1 / 2 \text { Enforcement Action Target }\end{array}$} & \multicolumn{4}{|c|}{$(-1,+1)$ Year Change } & \multicolumn{4}{|c|}{$(-1,+2)$ Year Change } \\
\hline & \multicolumn{2}{|c|}{$\begin{array}{c}\text { Industry-Size-Adjusted } \\
\text { ROA }\end{array}$} & \multicolumn{2}{|c|}{$\begin{array}{c}\text { Industry-Size-Adjusted } \\
\text { OPCFROA } \\
\end{array}$} & \multicolumn{2}{|c|}{$\begin{array}{c}\text { Industry-Size-Adjusted } \\
\text { ROA } \\
\end{array}$} & \multicolumn{2}{|c|}{$\begin{array}{c}\text { Industry-Size-Adjusted } \\
\text { OPCFROA }\end{array}$} \\
\hline & 0.0010 & $(0.82)$ & 0.0012 & $(0.88)$ & $0.0025 * *$ & $(2.18)$ & $0.0028 * *$ & $(2.23)$ \\
\hline Observations & \multicolumn{2}{|c|}{723} & \multicolumn{2}{|c|}{723} & \multicolumn{2}{|c|}{728} & \multicolumn{2}{|c|}{728} \\
\hline No of M\&As with a punished target (on support) & \multicolumn{2}{|c|}{82} & \multicolumn{2}{|c|}{82} & \multicolumn{2}{|c|}{82} & \multicolumn{2}{|c|}{82} \\
\hline Pseudo R-sq. & \multicolumn{2}{|c|}{0.003} & \multicolumn{2}{|c|}{0.003} & \multicolumn{2}{|c|}{0.003} & \multicolumn{2}{|c|}{0.003} \\
\hline
\end{tabular}

Panel B: Comparison Group is Banks not Engaged in M\&As

\begin{tabular}{|c|c|c|c|c|}
\hline \multirow{3}{*}{$\begin{array}{l}\text { ATT } \\
\text { Outcome variable: (Change in:) } \\
\text { Punished with Class } 1 / 2 \text { Enforcement Action Target }\end{array}$} & \multicolumn{2}{|c|}{$(-1,+1)$ Year Change } & \multicolumn{2}{|c|}{$(-1,+2)$ Year Change } \\
\hline & $\begin{array}{c}\text { Industry-Size-Adjusted } \\
\text { ROA }\end{array}$ & $\begin{array}{c}\text { Industry-Size-Adjusted } \\
\text { OPCFROA }\end{array}$ & $\begin{array}{c}\text { Industry-Size-Adjusted } \\
\text { ROA }\end{array}$ & $\begin{array}{c}\text { Industry-Size-Adjustec } \\
\text { OPCFROA }\end{array}$ \\
\hline & $0.0010 \quad(0.83)$ & $0.0006 \quad(0.038)$ & $0.0036 * * * \quad(2.59)$ & $0.0040 * * * \quad(2.59)$ \\
\hline Observations & 59,754 & 59,760 & 54,637 & 54,637 \\
\hline No of M\&As with a punished target (on support) & 87 & 87 & 81 & 81 \\
\hline Pseudo R-sq. & 0.011 & 0.011 & 0.011 & 0.011 \\
\hline
\end{tabular}


Figure I

Cross-sectional median of the industry-size adjusted ROA in the period of eight quarters before the M\&A becomes effective (denoted as $t=0$ )

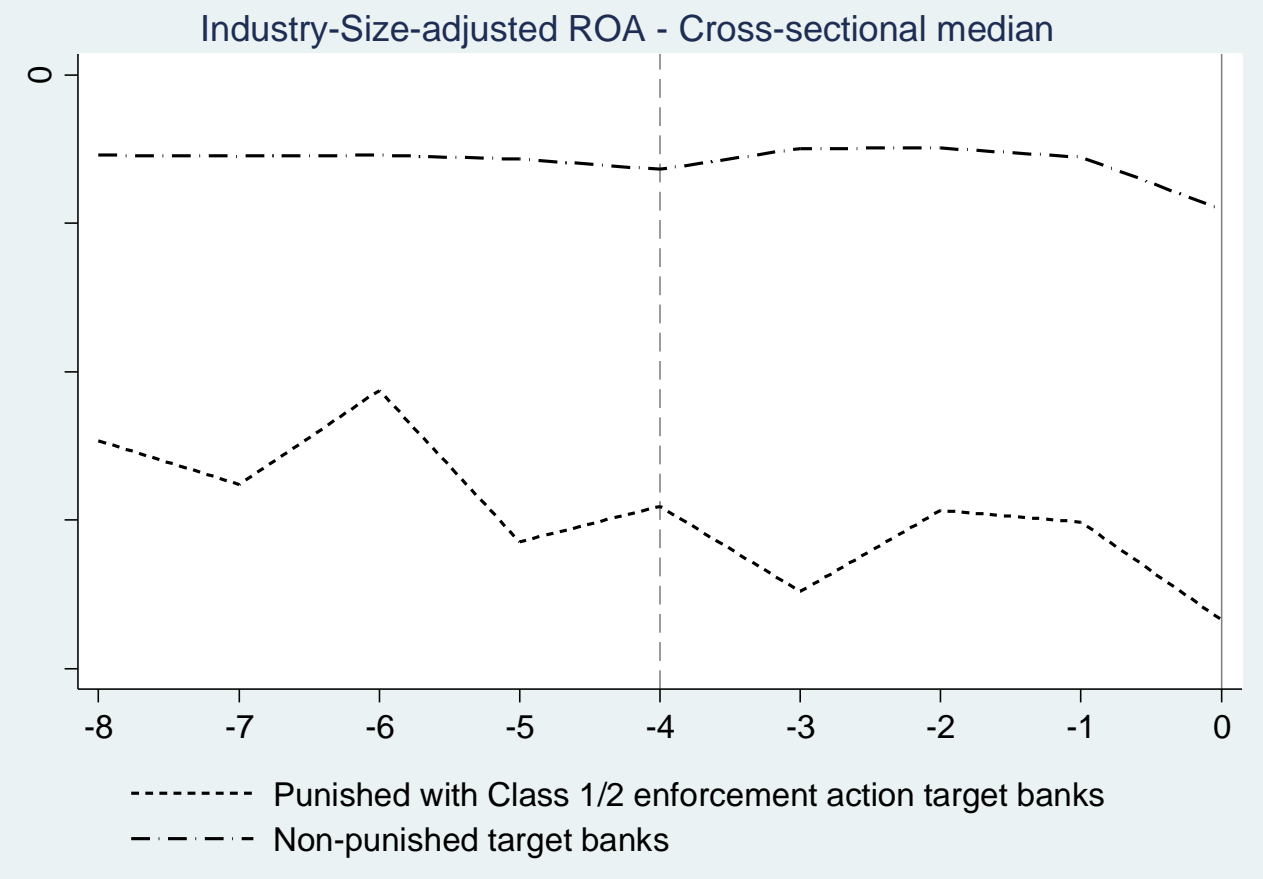


Figure II. Enforcement Actions and Acquisition Likelihood: Sensitivity - Literature Model

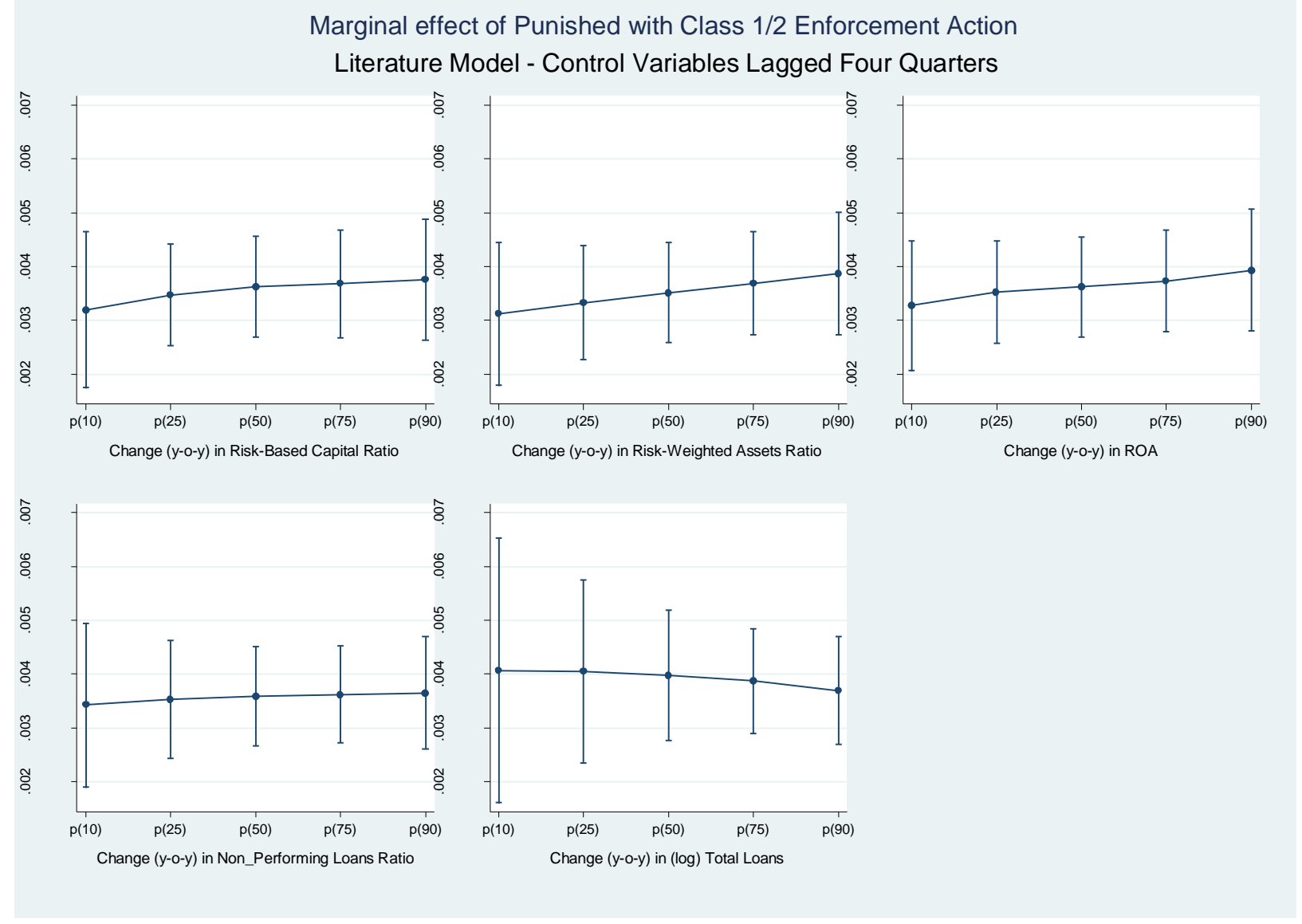

Marginal effect of Punished with Class 1/2 Enforcement Action

Literature Model - Control Variables Lagged One Quarter
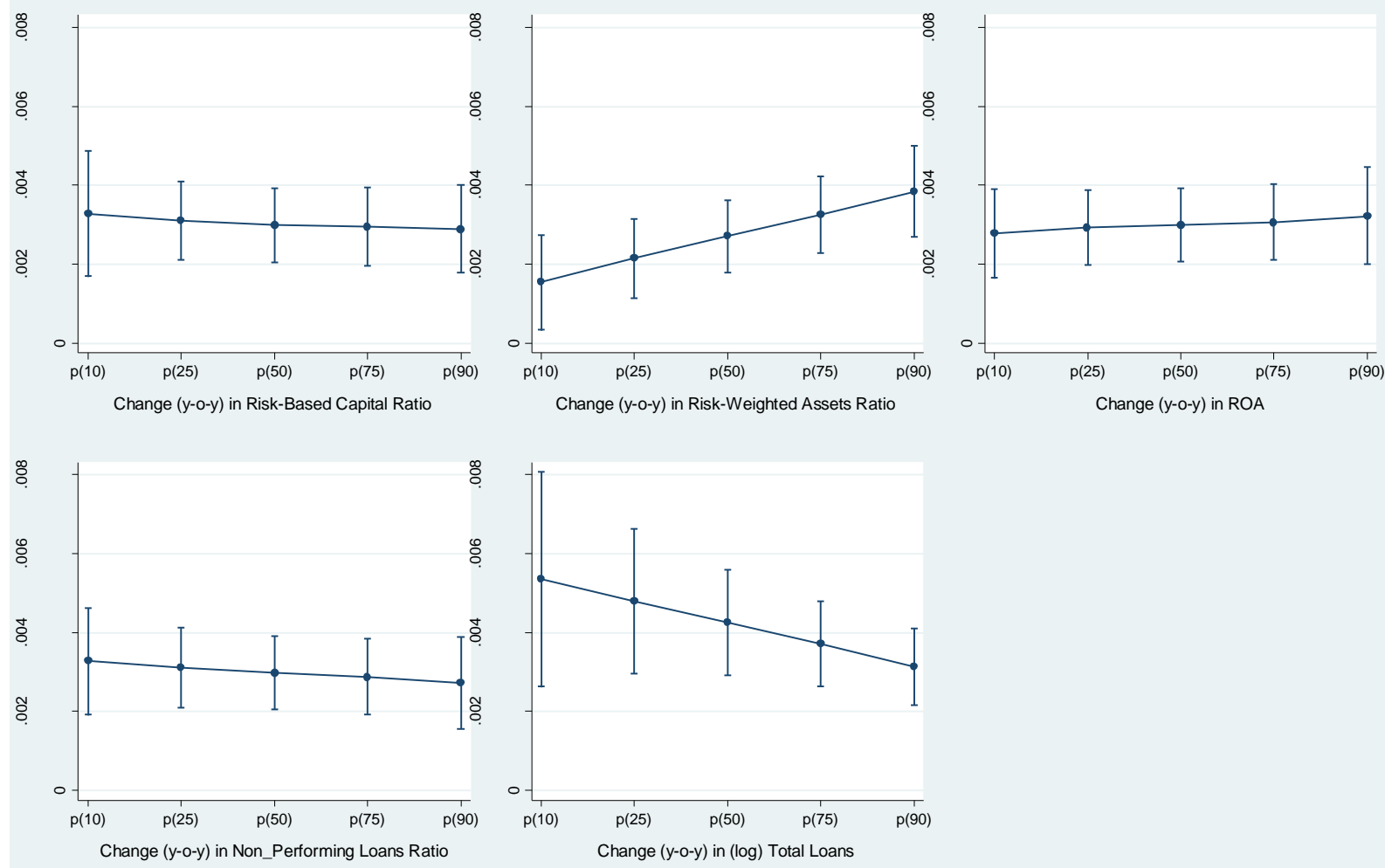
Figure III. Enforcement Actions and Acquisition Likelihood: Sensitivity - Enhanced Model

Marginal effect of Punished with Class 1/2 Enforcement Action

Enhanced Model - Control Variables Lagged Four Quarters
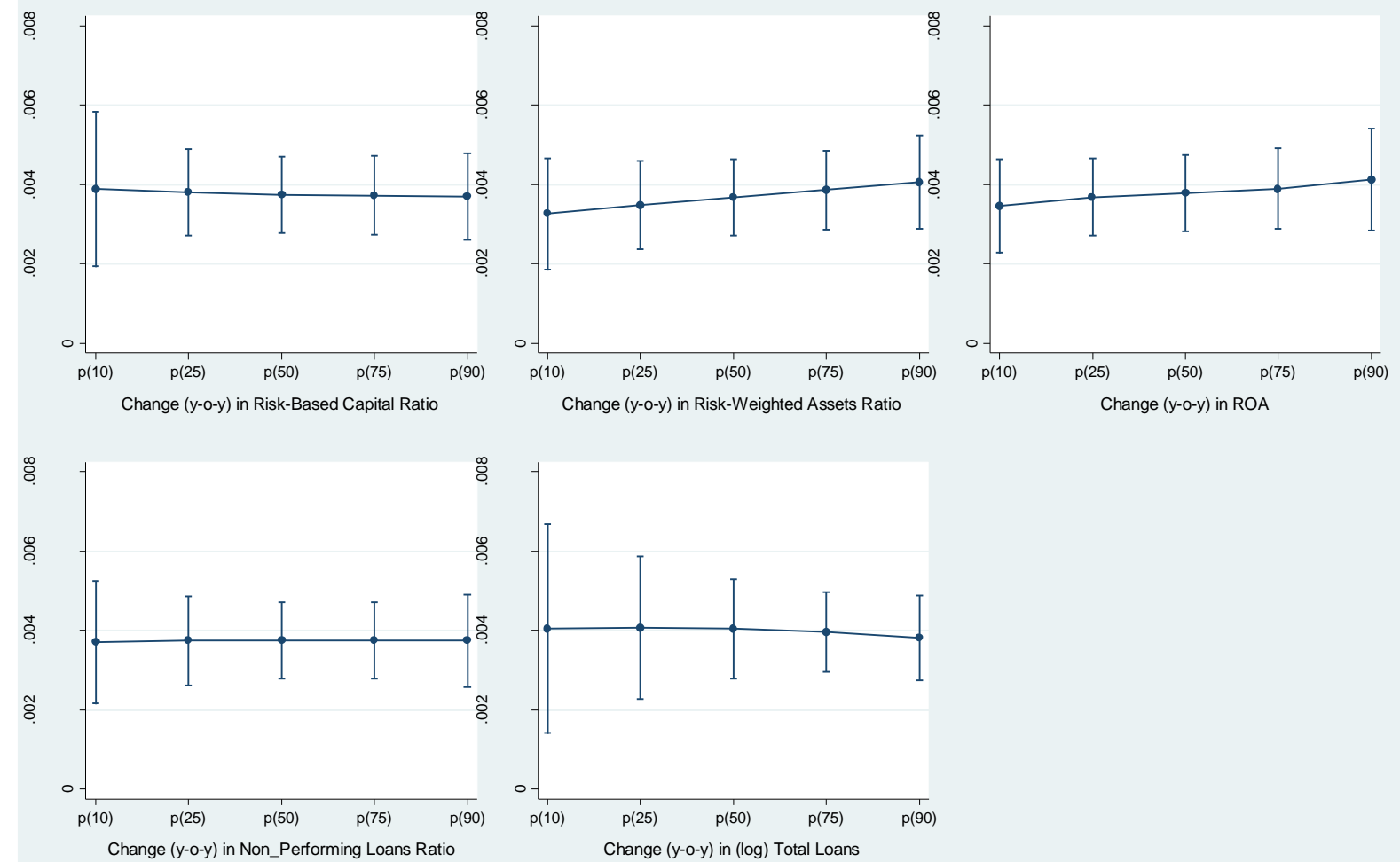

Marginal effect of Punished with Class 1/2 Enforcement Action

Enhanced Model - Control Variables Lagged One Quarter
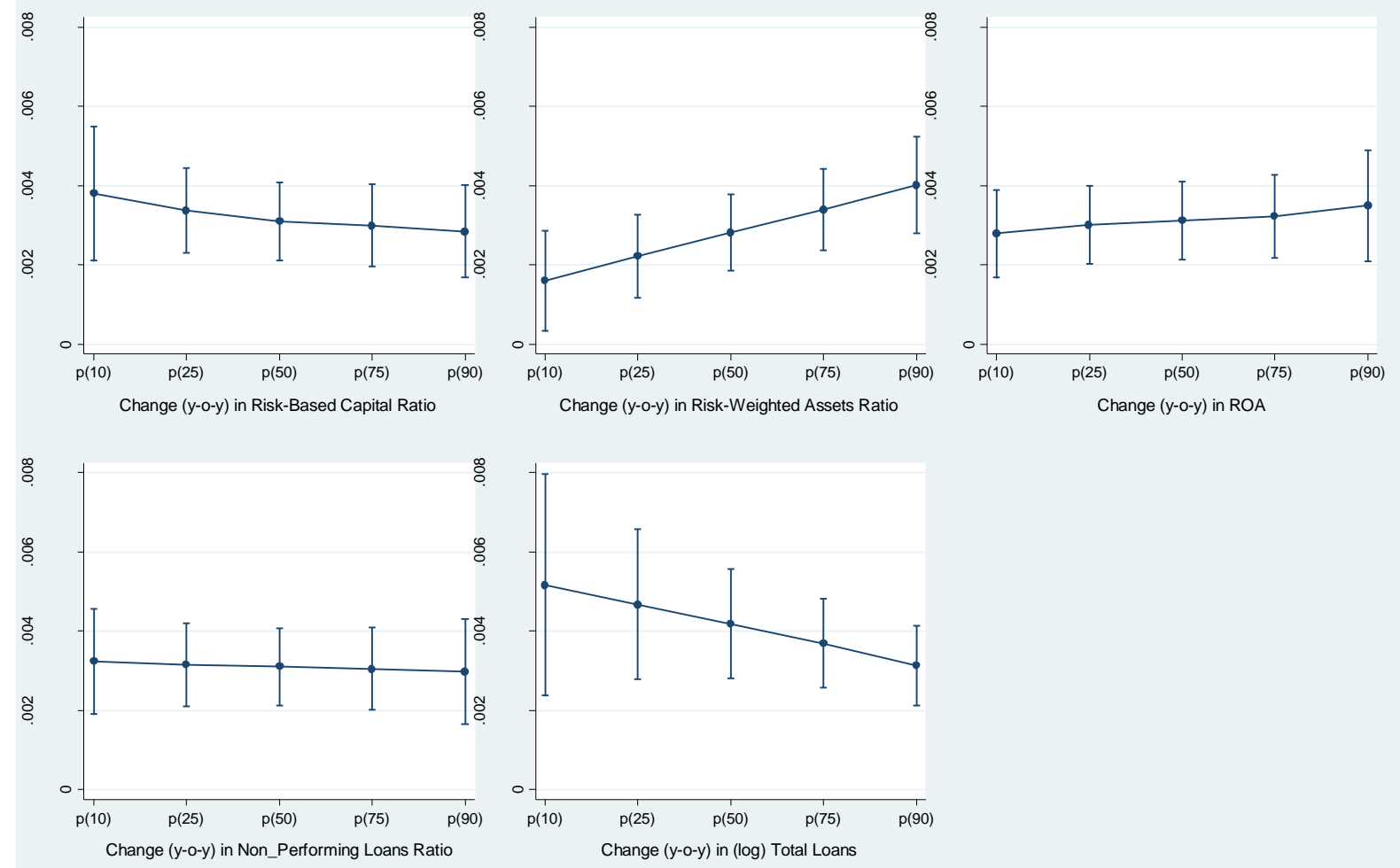


\title{
Online Appendix for the Manuscript:
}

\author{
Punished banks' acquisitions:
}

\author{
Evidence from the U.S. banking industry
}

\section{List of variables and definitions}

\section{Online Appendix Table I - List of Variables and Definitions}

Part I: First Stage of Analysis: Acquisition Likelihood of a Punished Bank

\begin{tabular}{|c|c|}
\hline Variable & Definition \\
\hline \multicolumn{2}{|r|}{ Panel A. Dependent Variable } \\
\hline Target & $\begin{array}{l}\text { A dummy variable that equals } 1 \text { for the target bank-quarter preceding the quarter } \\
\text { during which an M\&A deal, not involving a failed and ceased to exist bank as target, } \\
\text { becomes effective and } 0 \text { otherwise. This is because in almost all cases the call report } \\
\text { data for the target covering the quarter that the M\&A deal becomes effective is not } \\
\text { available due to the charter discontinued characteristic of the M\&As examined. } \\
\text { Only M\&A cases where there is a change in control are considered. }\end{array}$ \\
\hline
\end{tabular}

\section{Panel B. Explanatory Variables}

Information for bank financial characteristics variables is from the FFIEC 031/041 call reports, available from the Federal Reserve Bank of Chicago up to 2010Q4 and from the Central Data Repository's Public Data Distribution website from 2011Q1 onward.

Punished with Class 1/2 Enforcement Action

\section{Equity to Assets Ratio}

\section{Risk-Based Capital Ratio}

Risk-Weighted Assets Ratio

Operating Pre-Tax Cash Flow ROA (OPCFROA)

\section{ROA}

Standard Deviation of OPCFROA $\sigma($ OPCFROA )

Non-Performing Loans Ratio

Non-Interest Income Ratio

Inefficiency

Net Interest Margin

Liquidity Ratio

Trading Securities Ratio

Deposits to Assets Ratio

Loans to Assets Ratio
Dummy variable that equals 1 for the eight subsequent quarters after the quarter during which an enforcement action of Class 1 or 2 imposed on a bank becomes effective and 0 otherwise.

Book value of equity / book value of total assets

Total qualifying capital allowable under the risk-based capital guidelines / riskweighted assets net of allowances and other deductions

Risk-weighted assets net of allowances and other deductions / book value of total assets

Income or loss before income taxes and extraordinary items and other adjustments plus interest on subordinated debt and debentures / book value of total assets

Income or loss before income taxes and extraordinary items and other adjustments / book value of total assets

Standard deviation of OPCFROA, calculated for a rolling 12 quarters window

Nonaccrual total loans and lease finance receivables / total loans and leases net of unearned income

Total non-interest income / Total interest income plus total non-interest income

Total non-interest expenses / Total interest income plus total non-interest income minus total interest expenses

Total interest income minus total interest expenses / total loans and leases net of unearned income

Cash and balances due from depository institutions plus fair value of held to maturity US treasury securities / book value of total assets

Available for sale securities / book value of total assets

Total deposits / book value of total assets

Total loans and leases net of unearned income / book value of total assets 
Size

Market Share

Multi-state dummy

Bank Age

Gender of Supervisor's Bank Examiners
Natural logarithm of bank's book value of total assets

The weighted average deposit-based market share of a bank in all markets where that bank has a branch. For the calculation of this variable we employ the Summary of Deposits data from FDIC and use the county as the market unit.

A dummy variable that equals 1 for all bank quarters a bank is present through its branches in more than one state and 0 otherwise. Information for this variable comes from the Summary of Deposits files.

Natural logarithm of one plus the number of years since a bank became active. Data for this variable is from the rssd9950 series in call reports.

\section{Instrumental Variable}

This variable is constructed by first calculating the ratio of female to the total of federal bank examiners by state and year (quarter from 2007Q3 onward) for the FDIC and the OCC. Data are from the FedScope Employment Cubes, and are available online from the Office of Personnel Management. Subsequently, we use this as dependent variable in two regressions (one for each supervisor) with state fixed effects and quarter dummies as explanatory variables. We use the residuals from these regressions as instrumental variable in equation (2). For more details, see the main text.

Part II: Second Stage of Analysis: Operating performance for the combined entity

\begin{tabular}{l|l}
\hline Variable & Definition \\
\hline \multicolumn{1}{c|}{ Panel A. Dependent Variables }
\end{tabular}

Change in industry-size-adjusted ROA

(OPCFROA) of the combined entity in the

$(-1,+1) ;(-1,+2)$ time frame around the year

the M\&A deal becomes effective.
Information on the construction of this variable is provided in the main text

\section{Panel B. Explanatory Variables}

Information for bank financial characteristics is from the FFIEC 031/041 call reports. Information for the deal related variables is from SNL Financial.

Punished with Class 1/2 Enforcement

Action Target

Relative Size

Acquirer's Total Assets

Change in Equity to Assets Ratio

Change in Subordinated Debt to Assets Ratio

Private Equity Dummy

In-State Buyer Dummy

Geographic Market Expansion

Branch Ratio
Dummy variable that equals 1 if the target bank in an M\&A deal has been punished with an enforcement action of Class 1 or 2 that has become effective in any of eight quarters preceding the quarter the M\&A becomes effective, and 0 otherwise.

Ratio of the target's book value of total assets to acquirer's book value of total assets at the end of the year before the quarter the M\&A becomes effective.

Natural logarithm of the acquirer's book value of total assets at the end of the year before the quarter the M\&A becomes effective

Change in the book value of equity to book value of assets ratio of the combined entity at the end of the 1 or 2 years following the year of the M\&A minus the artificially combined entity's equity to assets at the end of the year before the M\&A becomes effective, using the book value of assets of the acquirer and the target as weights.

Change in the book value of subordinated debt and debentures (rcon3200) to book value of assets ratio of the combined entity at the end of the 1 or 2 years following the year of the M\&A minus the artificially combined entity's subordinated debt and debentures to assets at the end of the year before the M\&A deal, using the book value of assets of the acquirer and the target as weights.

Dummy variable that equals 1 if there is private equity involvement in the M\&A deal and 0 otherwise.

Dummy variable that equals 1 if the acquirer is in the same state with the target and 0 otherwise.

Cardinal variable that equals 1 if the acquirer and the target operate in the same market; 2 if the M\&A deal results to the geographic expansion of the acquirer; and 3 if there is partial overlap between the markets the acquirer and the target operate.

Ratio of the target's number of branches to that of the acquirer's at the end of the year before the quarter the M\&A becomes effective 


\section{Additional results on the probability of punished bank acquisition \\ Online Appendix Table II. - Enforcement Actions and Acquisition Likelihood for One Year after Punishment}

The table replicates the results of Table III, where the Punished with Class 1/2 Enforcement Action - 1 year is a dummy variable that equals 1 for the four subsequent quarters after the quarter during which a Class 1 or 2 enforcement action imposed on a bank becomes effective and 0 otherwise. The dependent variable Target is a dummy variable that equals 1 for the target bank-quarter during which an M\&A deal (not involving a failed and ceased to exist bank as target) becomes effective and 0 otherwise. Marginal effects and z-statistics (in parentheses) estimated from equation (1) with robust standard errors clustered by bank are presented. The sample period is 1999Q12015Q4. Two different models are employed, the 'Literature' model and the 'Enhanced' model reported in Panels A and B, respectively, the second being enhanced with variables proxying for the CAMELS rating of a bank. All explanatory variables, except for the Punished with Class 1/2 Enforcement Action- 1 year, are lagged either four quarters, or one quarter. A full set of time dummies is included in all regressions. For the variables' definitions and sources, see Table I, Part I, in the Online Appendix. The $* * *, * *$, and $*$ marks denote statistical significance at the 1,5 , and $10 \%$ level, respectively.

\begin{tabular}{|c|c|c|c|c|c|c|c|c|}
\hline \multirow[b]{3}{*}{ Punished with Class 1/2 Enforcement Action - 1 year } & \multicolumn{4}{|c|}{ Panel A: Literature model } & \multicolumn{4}{|c|}{ Panel B: Enhanced model } \\
\hline & \multicolumn{2}{|c|}{$\begin{array}{l}\text { Control variables lagged } \\
\text { four quarters }\end{array}$} & \multicolumn{2}{|c|}{$\begin{array}{c}\text { Control variables lagged } \\
\text { one quarter }\end{array}$} & \multicolumn{2}{|c|}{$\begin{array}{l}\text { Control variables lagged } \\
\text { four quarters }\end{array}$} & \multicolumn{2}{|c|}{$\begin{array}{c}\text { Control variables lagged } \\
\text { one quarter }\end{array}$} \\
\hline & $0.008 * * *$ & $(6.25)$ & $0.008 * * *$ & $(6.53)$ & $0.008 * * *$ & $(5.52)$ & $0.007 * * *$ & $(5.13)$ \\
\hline Equity to Assets Ratio & $-0.024 * * *$ & $(-7.65)$ & $-0.019 * * *$ & $(-6.12)$ & & & & \\
\hline Risk-Based Capital Ratio & & & & & $-0.006 * * *$ & $(-2.78)$ & $-0.007 * * *$ & $(-2.91)$ \\
\hline Risk-Weighted Assets Ratio & & & & & $-0.003 * *$ & $(-2.04)$ & $-0.003 * *$ & $(-2.52)$ \\
\hline Operating Pre-Tax Cash Flow ROA (OPCFROA) & $-0.025 * *$ & $(-2.46)$ & $-0.020 * *$ & $(-2.50)$ & -0.015 & $(-0.64)$ & $-0.034 * * *$ & $(-3.14)$ \\
\hline$\sigma(\mathrm{OPCFROA})$ & & & & & -0.004 & $(-0.23)$ & $-0.019 * * *$ & $(-3.05)$ \\
\hline Non-Performing Loans Ratio & & & & & $0.023 * * *$ & $(2.89)$ & 0.012 & $(1.51)$ \\
\hline Non-Interest Income Ratio & & & & & $-0.002 * *$ & $(-2.28)$ & $-0.002 * *$ & $(-2.03)$ \\
\hline Inefficiency & $0.001 * * *$ & $(5.18)$ & $0.001 * * *$ & $(5.61)$ & $0.002 * * *$ & $(7.11)$ & $0.002 * * *$ & $(6.26)$ \\
\hline Net Interest Margin & $0.002 * *$ & $(2.41)$ & $0.001 *$ & $(1.70)$ & $0.003 * * *$ & $(3.93)$ & $0.003 * * *$ & $(4.43)$ \\
\hline Liquidity Ratio & $0.009 * * *$ & $(6.37)$ & $0.011 * * *$ & $(8.05)$ & $0.010 * * *$ & $(6.02)$ & $0.012 * * *$ & $(7.70)$ \\
\hline Loans to Assets Ratio & -0.001 & $(-1.17)$ & -0.001 & $(-1.14)$ & -0.001 & $(-0.98)$ & -0.001 & $(-0.78)$ \\
\hline Deposits to Assets Ratio & $-0.002 *$ & $(-1.80)$ & $-0.003 * *$ & $(-2.22)$ & $-0.003 * *$ & $(-2.09)$ & $-0.004 * * *$ & $(-3.04)$ \\
\hline Size & $0.0003 * * *$ & $(3.29)$ & $0.0004 * * *$ & $(3.89)$ & $0.0004 * * *$ & $(3.49)$ & $0.0004 * * *$ & $(4.27)$ \\
\hline Market Share & $-0.003 * * *$ & $(-3.18)$ & $-0.003 * * *$ & $(-3.49)$ & $-0.002 * * *$ & $(-2.95)$ & $-0.003 * * *$ & $(-3.20)$ \\
\hline Multi-state Dummy & -0.001 & $(-1.57)$ & $-0.001 *$ & $(-1.93)$ & $-0.001 *$ & $(-1.76)$ & $-0.001^{* *}$ & $(-2.26)$ \\
\hline Bank Age & $-0.001 * * *$ & $(-9.78)$ & $-0.001 * * *$ & $(-8.42)$ & $-0.001 * * *$ & $(-12.66)$ & $-0.001 * * *$ & $(-12.55)$ \\
\hline Time Fixed Effects & Yes & & Yes & & Yes & & Yes & \\
\hline Pseudo R-squared & 0.028 & & 0.027 & & 0.034 & & 0.034 & \\
\hline Number of Banks & 10,901 & & 11,068 & & 10,116 & & 10,322 & \\
\hline Observations & 438,553 & & 453,829 & & 409,029 & & 421,678 & \\
\hline
\end{tabular}


Online Appendix Table III - Enforcement Actions and Acquisition Likelihood:

Only Target Banks in the M\&A deals Used to Test the Second Hypothesis are Employed in the Dependent Variable

The table replicates the results of Table III, where the dependent variable Target is a dummy variable that equals 1 only for the target bank-quarter during which each of the 752 M\&A deals employed in Table VII becomes effective and 0 otherwise. The Punished with Class 1/2 Enforcement Action is a dummy variable that equals 1 for the eight subsequent quarters after the quarter during which a Class 1 or 2 enforcement action imposed on a bank becomes effective and 0 otherwise. Marginal effects and z-statistics (in parentheses) of equation (1) estimated with robust standard errors clustered by bank are presented. Two different models are employed, the "Literature" model and the "Enhanced model" reported in Panels A and B, respectively, the second being enhanced with variables proxying for the CAMELS rating of a bank. All explanatory variables, except for the Punished with Class 1/2 Enforcement Action, are lagged either eight quarters or four quarters. A full set of time dummies is included in all regressions. For the variables' definitions and sources, see Table I, Part I, in the Online Appendix. The sample period is 1999Q1-2015Q4. The ***,**, and * marks denote statistical significance at the 1,5 , and $10 \%$ level, respectively.

\begin{tabular}{|c|c|c|c|c|c|c|c|c|}
\hline \multirow[b]{3}{*}{ Punished with Class 1/2 Enforcement Action } & \multicolumn{4}{|c|}{ Panel A: Literature Model } & \multicolumn{4}{|c|}{ Panel B: Enhanced Model } \\
\hline & \multicolumn{2}{|c|}{$\begin{array}{l}\text { Control variables lagged } \\
\text { eight quarters }\end{array}$} & \multicolumn{2}{|c|}{$\begin{array}{l}\text { Control variables lagged } \\
\text { four quarters }\end{array}$} & \multicolumn{2}{|c|}{$\begin{array}{c}\text { Control variables lagged } \\
\text { eight quarters }\end{array}$} & \multicolumn{2}{|c|}{$\begin{array}{l}\text { Control variables lagged } \\
\text { four quarters }\end{array}$} \\
\hline & $0.004 * * *$ & $(6.08)$ & $0.003 * * *$ & $(5.62)$ & $0.004 * * *$ & $(5.57)$ & $0.004 * * *$ & $(5.21)$ \\
\hline Equity to Assets Ratio & $-0.011 * * *$ & $(-5.51)$ & $-0.013 * * *$ & $(-7.12)$ & & & & \\
\hline Risk-Based Capital Ratio & & & & & $-0.003 * * *$ & $(-2.62)$ & $-0.004 * * *$ & $(-3.25)$ \\
\hline Risk-Weighted Assets Ratio & & & & & $-0.002 *$ & $(-1.75)$ & $-0.002 * *$ & $(-2.55)$ \\
\hline Operating Cash Flow & $-0.006 * *$ & $(-2.05)$ & $-0.007 * * *$ & $(-2.94)$ & $-0.018 * *$ & $(-2.52)$ & $-0.025 * * *$ & $(-3.98)$ \\
\hline$\sigma($ Operating Cash Flow) & & & & & $-0.052 * *$ & $(-2.24)$ & $-0.055^{* *}$ & $(-2.57)$ \\
\hline Non-Performing Loans Ratio & & & & & 0.001 & $(0.23)$ & 0.0001 & $(0.02)$ \\
\hline Non-Interest Income Ratio & & & & & $-0.002 * *$ & $(-2.52)$ & $-0.001 * *$ & $(-2.25)$ \\
\hline Inefficiency & $0.0003 * * *$ & $(3.52)$ & $0.0003 * * *$ & $(4.10)$ & $0.001 * * *$ & $(5.98)$ & $0.001 * * *$ & $(6.86)$ \\
\hline Net Interest Margin & -0.001 & $(-0.90)$ & -0.002 & $(-1.36)$ & $0.001 *$ & $(1.72)$ & 0.0004 & $(0.96)$ \\
\hline Liquidity Ratio & $0.003 * * *$ & $(3.71)$ & $0.003 * * *$ & $(3.30)$ & $0.004 * * *$ & $(4.25)$ & $0.003 * * *$ & $(3.47)$ \\
\hline Loans to Assets Ratio & $-0.001 * *$ & $(-2.40)$ & $-0.001 * * *$ & $(-2.93)$ & -0.001 & $(-0.83)$ & -0.001 & $(-0.93)$ \\
\hline Size & $-0.001 * * *$ & $(-8.38)$ & $-0.001 * * *$ & $(-8.83)$ & $-0.001 * * *$ & $(-7.35)$ & $-0.001 * * *$ & $(-7.47)$ \\
\hline Market Share & $-0.001 * *$ & $(-2.43)$ & $-0.001 * *$ & $(-2.40)$ & $-0.001^{*}$ & $(-1.87)$ & $-0.001 *$ & $(-1.76)$ \\
\hline Multi-state Dummy & 0.0001 & $(0.30)$ & 0.0001 & $(0.33)$ & -0.0002 & $(-0.48)$ & -0.0002 & $(-0.48)$ \\
\hline Bank Age & $-0.0003 * * *$ & $(-5.04)$ & $-0.0003 * * *$ & $(-4.74)$ & $-0.0005 * * *$ & $(-6.69)$ & $-0.0005 * * *$ & $(-7.26)$ \\
\hline Time Fixed Effects & \multicolumn{2}{|c|}{ Yes } & \multicolumn{2}{|c|}{ Yes } & \multicolumn{2}{|c|}{ Yes } & \multicolumn{2}{|c|}{ Yes } \\
\hline Pseudo R-squared & \multicolumn{2}{|c|}{0.048} & \multicolumn{2}{|c|}{0.047} & \multicolumn{2}{|c|}{0.056} & \multicolumn{2}{|c|}{0.055} \\
\hline Number of Banks & \multicolumn{2}{|c|}{10,364} & \multicolumn{2}{|c|}{10,901} & \multicolumn{2}{|c|}{9,582} & \multicolumn{2}{|c|}{10,116} \\
\hline Observations & \multicolumn{2}{|c|}{396,069} & \multicolumn{2}{|c|}{438,553} & \multicolumn{2}{|c|}{371,280} & \multicolumn{2}{|c|}{409,029} \\
\hline
\end{tabular}




\section{Online Appendix Table IV - Enforcement Actions and Acquisition Likelihood: \\ Results for Different Ownership Statuses of Targets or Acquirers in M\&As}

The table reports marginal effects and z-statistics (in parentheses) of equation (1) estimated with robust standard errors clustered by bank. The sample includes only the banks that participated as targets in M\&As during the sample period, i.e., 1999Q1-2015Q4. We construct four dummy variables that take the value of 1 at the quarter the M\&A deal becomes effective and according to the ownership status of the target or the acquiring bank at the time of the deal, and 0 otherwise. Only M\&A cases where there is a change in control and not involving a failed and ceased to exist bank as target are considered. These variables, denoted Single target, BHC member target, Target Acquired by Single Acquirer, and Target Acquired by BHC Member Acquirer are then used as dependent variables in equation (1). The Punished with Class 1/2 Enforcement Action is a dummy variable that equals 1 for the eight subsequent quarters after the quarter during which a Class 1 or 2 enforcement action imposed on a bank becomes effective and 0 otherwise. The "Literature" model is employed in all columns with control variables lagged four quarters. A full set of time dummies is included in all regressions. For brevity, only the coefficients of interest are reported. The ***,**, and * marks denote statistical significance at the 1,5 , and $10 \%$ level, respectively.

\begin{tabular}{|c|c|c|c|c|}
\hline Dependent variable: & Single Target & $\begin{array}{c}\text { BHC Member } \\
\text { Target }\end{array}$ & $\begin{array}{c}\text { Target Acquired } \\
\text { by Single } \\
\text { Acquirer }\end{array}$ & $\begin{array}{c}\text { Target Acquired } \\
\text { by BHC Member } \\
\text { Acquirer }\end{array}$ \\
\hline Punished with Class $1 / 2$ Enforcement Action & $0.012 * * * \quad(3.77)$ & $0.016^{* * *} \quad(4.01)$ & $0.008 * * * \quad(3.32)$ & $0.020 * * * \quad(4.36)$ \\
\hline Time Fixed Effects & Yes & Yes & Yes & Yes \\
\hline Pseudo R-squared & 0.072 & 0.089 & 0.0056 & 0.0091 \\
\hline
\end{tabular}




\section{Online Appendix Table V - Descriptive Statistics for Changes in Fundamentals Across Punished and Non-Punished Bank-Quarters}

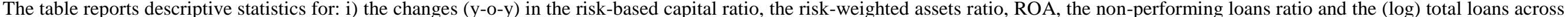

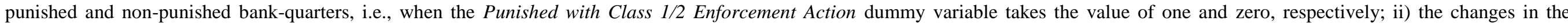

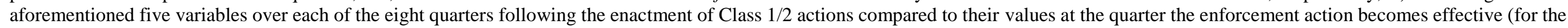

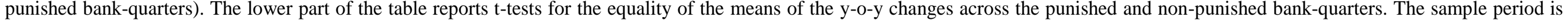
1999Q1-2015Q4.

\begin{tabular}{|c|c|c|c|c|c|c|c|c|c|c|}
\hline & Obs. & Mean & St. Dev. & Min & Max & $\mathrm{p} 10$ & $\mathrm{p} 25$ & $\mathrm{p} 50$ & p75 & p90 \\
\hline \multicolumn{11}{|l|}{ Change (y-o-y) in Risk-Based Capital Ratio: } \\
\hline Non-Punished Bank-Quarters & 459,374 & -0.0041 & 0.0455 & -0.6514 & 0.6332 & -0.0252 & -0.0099 & -0.0002 & 0.0084 & 0.0191 \\
\hline Punished Bank-Quarters & 16,786 & 0.0044 & 0.0464 & -0.6267 & 0.6244 & -0.0344 & -0.0106 & 0.0049 & 0.0187 & 0.0369 \\
\hline $\begin{array}{l}\text { Change in Risk-Based Capital Ratio Relative to } \\
\text { Enforcement Quarter Value for Punished Bank- } \\
\text { Quarters }\end{array}$ & 16,870 & 0.0080 & 0.0405 & -0.4224 & 0.4903 & -0.0261 & -0.0065 & 0.0048 & 0.0201 & 0.0413 \\
\hline \multicolumn{11}{|l|}{ Change (y-o-y) in Risk-Weighted Assets Ratio: } \\
\hline Non-Punished Bank-Quarters & 456,455 & 0.0039 & 0.0555 & -0.3116 & 0.3189 & -0.0557 & -0.0241 & 0.0038 & 0.0314 & 0.0628 \\
\hline Punished Bank-Quarters & 16,653 & -0.0220 & 0.0638 & -0.3058 & 0.3109 & -0.0976 & -0.0577 & -0.0205 & 0.0144 & 0.0509 \\
\hline $\begin{array}{l}\text { Change in Risk-Weighted Assets Ratio Relative } \\
\text { to Enforcement Quarter Value For Punished } \\
\text { Bank-Quarters }\end{array}$ & 16,817 & -0.0214 & 0.0659 & -0.4580 & 0.4486 & -0.0986 & -0.0532 & -0.0161 & 0.0130 & 0.0456 \\
\hline \multicolumn{11}{|l|}{ Change (y-o-y) in ROA: } \\
\hline Non-Punished Bank-Quarters & 459,458 & 0.0001 & 0.0057 & -0.0468 & 0.0470 & -0.0039 & -0.0014 & $-1.63 \mathrm{E}-05$ & 0.0014 & 0.0040 \\
\hline Punished Bank-Quarters & 16,290 & 0.0005 & 0.0122 & -0.0468 & 0.0470 & -0.0125 & -0.0035 & 0.0003 & 0.0048 & 0.0140 \\
\hline $\begin{array}{l}\text { Change in ROA Relative to Enforcement Quarter } \\
\text { Value For Punished Bank-Quarters }\end{array}$ & 16,835 & 0.0012 & 0.0166 & -0.0899 & 0.0980 & -0.0144 & -0.0047 & 0.0005 & 0.0068 & 0.0186 \\
\hline \multicolumn{11}{|l|}{ Change (y-o-y) in Non-Performing Loans Ratio: } \\
\hline Non-Punished Bank-Quarters & 450,303 & 0.0005 & 0.0102 & -0.0556 & 0.0567 & -0.0088 & -0.0026 & 0.0000 & 0.0027 & 0.0106 \\
\hline Punished Bank-Quarters & 11,892 & -0.0007 & 0.0188 & -0.0557 & 0.0567 & -0.0241 & -0.0108 & -0.0005 & 0.0086 & 0.0237 \\
\hline $\begin{array}{l}\text { Change in Non-Performing Loans Ratio Relative } \\
\text { to Enforcement Quarter Value For Punished } \\
\text { Bank-Quarters }\end{array}$ & 12,252 & -0.0019 & 0.0197 & -0.0788 & 0.0779 & -0.0261 & -0.0106 & -0.0004 & 0.0067 & 0.0209 \\
\hline \multicolumn{11}{|l|}{ Change (y-o-y) in (log) Total Loans: } \\
\hline Non-Punished Bank-Quarters & 457,246 & 0.0845 & 0.1761 & -1.3041 & 1.4819 & -0.0652 & -0.0040 & 0.0589 & 0.1332 & 0.2453 \\
\hline Punished Bank-Quarters & 16,835 & -0.0841 & 0.1900 & -1.2882 & 1.4111 & -0.2712 & -0.1798 & -0.0917 & 0.0003 & 0.1121 \\
\hline $\begin{array}{l}\text { Change in (log) Total Loans Relative to } \\
\text { Enforcement Quarter Value For Punished Bank- }\end{array}$ & 16,959 & -0.0911 & 0.2134 & -2.5917 & 2.4709 & -0.3072 & -0.1793 & -0.0775 & -0.0027 & 0.0857 \\
\hline
\end{tabular}


Change (y-o-y) in Risk-Weighted Assets Ratio

$-0.0259 * * *$

Change (y-o-y) in ROA

$(-51.78)$

$0.0004 * * *$

(4.24)

$-0.0011^{* * * *}$

Change (y-o-y) in Non-Performing Loans Ratio

$(-6.43)$

$-0.1685 * * *$

Change (y-o-y) in (log) Total Loans

(113.36) 
Online Appendix Table VI - Enforcement Actions and Acquisition Likelihood: Sensitivity -

\section{Marginal Effect of the Punished with Class 1/2 Enforcement Action Dummy Variable at Different Degrees of}

\section{Improvement/Deterioration in Punished Banks' Fundamentals}

The table reports the marginal effect and z-statistic (in parentheses) for the Punished with Class 1/2 Enforcement Action dummy variable at different percentile values of the y-o-y changes in the risk-based capital ratio, the risk-weighted assets ratio, the non-performing loans ratio, and $R O A$ for the punished bank-quarters. The dependent variable Target is a dummy variable that equals 1 for the target bank-quarter during which an M\&A deal (not involving a failed and ceased to exist bank as target) becomes effective and 0 otherwise. Only M\&A cases where there is a change in control are considered. The Punished with Class 1/2 Enforcement Action is a dummy variable that equals 1 for the eight subsequent quarters after the quarter during which a Class 1 or 2 enforcement action imposed on a bank becomes effective and 0 otherwise. Two different models are employed, the "Literature" model and the "Enhanced" model reported in Panels A and B, respectively, the second being enhanced with variables proxying for the CAMELS rating of a bank. All explanatory variables, except for the Punished with Class 1/2 Enforcement Action, are lagged either four quarters or one quarter. A full set of time dummies is included in all regressions, estimated with robust standard errors clustered by bank. For brevity, only the coefficients of interest are reported. For the variables' definitions and sources, see Table I, Part I, in the Online Appendix. The sample period is 1999Q1-2015Q4. The $* * *, * *$, and $*$ marks denote statistical significance at the 1,5 , and $10 \%$ level, respectively.

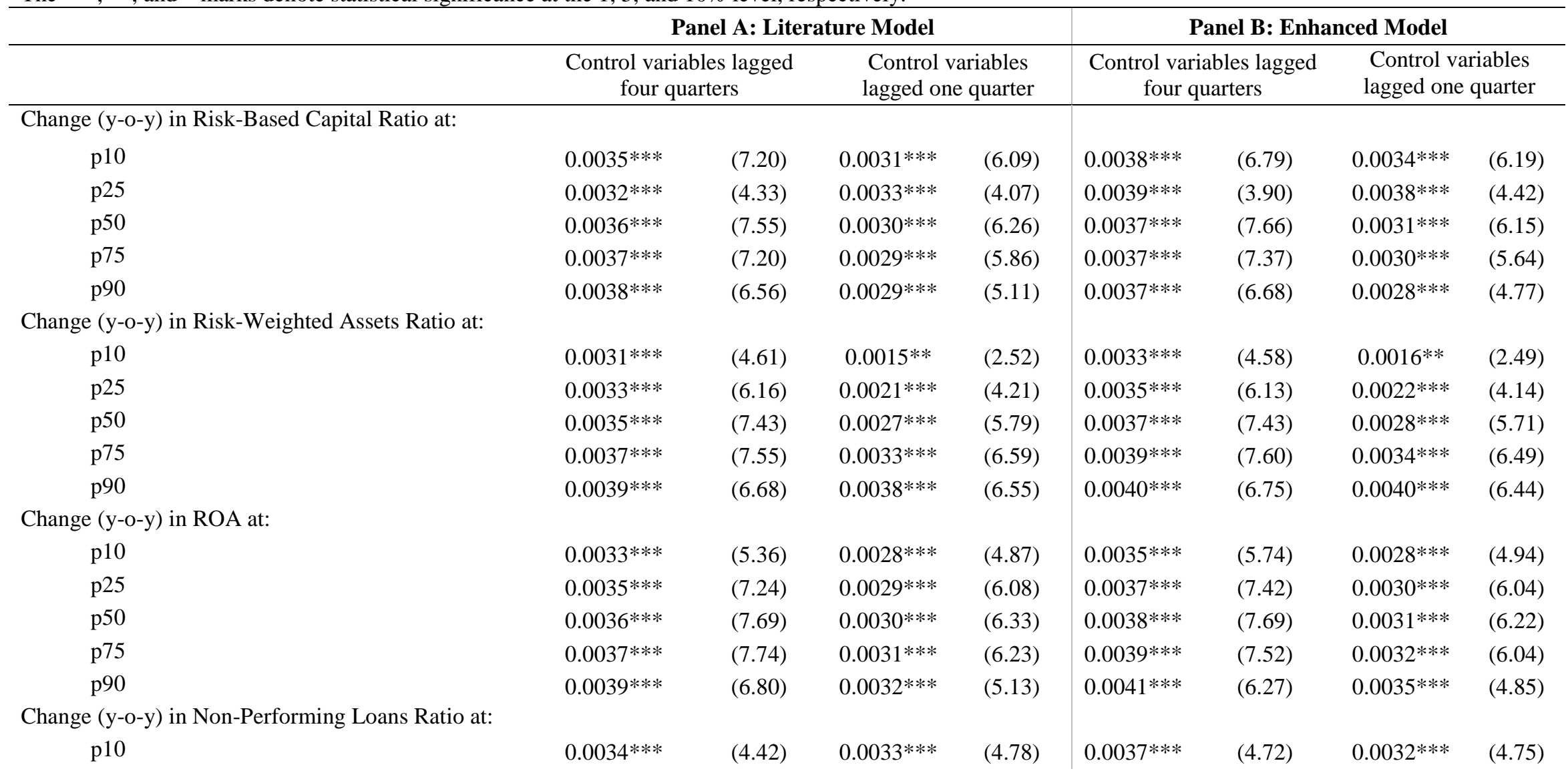




\begin{tabular}{|c|c|c|c|c|c|c|c|c|}
\hline $\mathrm{p} 25$ & $0.0035^{* * *}$ & (6.29) & $0.0031^{* * *}$ & $(5.96)$ & $0.0037 * * *$ & $(6.52)$ & $0.0032 * * *$ & $(5.91)$ \\
\hline $\mathrm{p} 50$ & $0.0036^{* * *}$ & (7.60) & $0.0030 * * *$ & $(6.32)$ & $0.0038^{* * *}$ & (7.64) & $0.0031 * * *$ & $(6.22)$ \\
\hline p75 & $0.0036 * * *$ & (7.92) & $0.0029 * * *$ & $(5.91)$ & $0.0038 * * *$ & (7.68) & $0.0030 * * *$ & $(5.74)$ \\
\hline p90 & $0.0037 * * *$ & $(6.82)$ & $0.0027 * * *$ & $(4.60)$ & $0.0037 * * *$ & $(6.30)$ & $0.0030 * * *$ & $(4.38)$ \\
\hline \multicolumn{9}{|c|}{ Change (y-o-y) in (log) Total Loans at: } \\
\hline p10 & $0.0041 * * *$ & $(3.25)$ & $0.0054 * * *$ & $(3.87)$ & $0.0040 * * *$ & $(3.01)$ & $0.0052 * * *$ & $(3.62)$ \\
\hline p25 & $0.0041 * * *$ & (4.68) & $0.0048 * * *$ & (5.13) & $0.0041 * * *$ & (4.45) & $0.0047 * * *$ & $(4.83)$ \\
\hline p50 & $0.0040 * * *$ & (6.46) & $0.0043 * * *$ & $(6.25)$ & $0.0040 * * *$ & (6.33) & $0.0042 * * *$ & $(5.92)$ \\
\hline p75 & $0.0039 * * *$ & (7.79) & $0.0037 * * *$ & (6.73) & $0.0040 * * *$ & $(7.75)$ & $0.0037 * * *$ & $(6.46)$ \\
\hline $\mathrm{p} 90$ & $0.0037 * * *$ & (7.23) & $0.0031 * * *$ & $(6.31)$ & $0.0038 * * *$ & (6.97) & $0.0031 * * *$ & $(6.14)$ \\
\hline Control Variables & \multicolumn{2}{|c|}{ Yes } & \multicolumn{2}{|c|}{ Yes } & \multicolumn{2}{|c|}{ Yes } & \multicolumn{2}{|c|}{ Yes } \\
\hline Time Fixed Effects & \multicolumn{2}{|c|}{ Yes } & \multicolumn{2}{|c|}{ Yes } & \multicolumn{2}{|c|}{ Yes } & \multicolumn{2}{|c|}{ Yes } \\
\hline Pseudo R-squared & \multirow{2}{*}{\multicolumn{2}{|c|}{$\begin{array}{c}0.042 \\
10,307\end{array}$}} & \multirow{2}{*}{\multicolumn{2}{|c|}{0.046}} & \multicolumn{2}{|c|}{0.043} & \multicolumn{2}{|c|}{0.047} \\
\hline Number of Banks & & & & & \multirow{2}{*}{\multicolumn{2}{|c|}{$\begin{array}{c}9,636 \\
371,012\end{array}$}} & \multirow{2}{*}{\multicolumn{2}{|c|}{$\begin{array}{c}10,065 \\
398,283\end{array}$}} \\
\hline Observations & \multicolumn{2}{|c|}{381,865} & \multicolumn{2}{|c|}{$\begin{array}{c}10,727 \\
411.083\end{array}$} & & & & \\
\hline
\end{tabular}


III. Additional results for the second stage analysis

Online Appendix Table V - Propensity score estimation

\begin{tabular}{|c|c|c|c|c|}
\hline \multirow[b]{2}{*}{ Equity to Assets Ratio t-1 } & \multicolumn{2}{|c|}{$\begin{array}{c}\text { M\&As of punished target } \\
\text { banks vs M\&As of non- } \\
\text { punished target banks }\end{array}$} & \multicolumn{2}{|c|}{$\begin{array}{l}\text { M\&As of punished target } \\
\text { banks vs banks not engaged } \\
\text { in M\&As }\end{array}$} \\
\hline & -8.397 & $(-1.56)$ & $-8.820 * *$ & $(-2.39)$ \\
\hline Subordinated Debt to Assets Ratio $t-1$ & $60.175^{* *}$ & $(2.14)$ & 7.589 & $(0.36)$ \\
\hline Size $_{\mathrm{t}-1}$ & -0.134 & $(-1.35)$ & $0.803 * * *$ & $(12.88)$ \\
\hline$\Delta$ (Equity to Assets Ratio $)_{t-2}$ to t-1 & 3.970 & $(0.31)$ & 1.415 & $(0.18)$ \\
\hline$\Delta\left(\right.$ Subordinated Debt to Assets Ratio) ${ }_{t-2}$ to t -1 & -11.627 & $(-0.26)$ & -39.915 & $(-1.31)$ \\
\hline$\Delta(\mathrm{ROA}) \mathrm{t}-2$ to $\mathrm{t}-1$ & $58.596 * * *$ & $(2.63)$ & 4.999 & $(0.60)$ \\
\hline$\Delta($ Size $)$ t-2 to t-1 & $3.445 * *$ & $(2.30)$ & 1.299 & $(1.38)$ \\
\hline Relative Size ${ }_{t-1}$ & -0.238 & $(-0.62)$ & & \\
\hline Costant & 0.852 & $(0.57)$ & $-15.341 * * *$ & $(-17.95)$ \\
\hline Observations & \multicolumn{2}{|c|}{747} & \multicolumn{2}{|c|}{60,184} \\
\hline Pseudo R-squared & \multicolumn{2}{|c|}{0.044} & \multicolumn{2}{|c|}{0.112} \\
\hline Pseudo Log likelihood & \multicolumn{2}{|c|}{24.43} & \multicolumn{2}{|c|}{151.19} \\
\hline
\end{tabular}


Online Appendix Table V - Test of the balancing property

\begin{tabular}{|c|c|c|c|c|c|c|c|c|c|c|}
\hline \multirow[b]{2}{*}{ Variable } & \multicolumn{5}{|c|}{$\begin{array}{l}\text { Panel A. M\&As of punished target banks vs } \\
\text { M\&As of non-punished target banks }\end{array}$} & \multicolumn{5}{|c|}{$\begin{array}{c}\text { Panel B. M\&As of punished target banks } \\
\text { vs banks not engaged in M\&As } \\
\end{array}$} \\
\hline & Sample & Treated & Control & t-test & $\mathbf{p}>|\mathbf{t}|$ & Sample & Treated & Control & t-test & $\mathbf{p}>|\mathbf{t}|$ \\
\hline \multirow{2}{*}{ Propensity score } & UNMATCHED & 0.16061 & 0.11499 & 6.64 & 0.000 & UNMATCHED & 0.00661 & 0.00149 & 2.34 & 0.019 \\
\hline & MATCHED & 0.14625 & 0.14553 & 0.06 & 0.951 & MATCHED & 0.00661 & 0.00661 & 0 & 1 \\
\hline \multirow{2}{*}{ Equity to Assets Ratio $t-1$} & UNMATCHED & 0.09958 & 0.10472 & -1.89 & 0.059 & UNMATCHED & 0.09958 & 0.11204 & -2.74 & 0.006 \\
\hline & MATCHED & 0.10084 & 0.10155 & -0.23 & 0.819 & MATCHED & 0.1 & 0.09961 & 0.1 & 0.918 \\
\hline \multirow{2}{*}{ Subordinated Debt to Assets Ratio t-1 } & UNMATCHED & 0.00199 & 0.00082 & 2.57 & 0.01 & UNMATCHED & 0.00199 & 0.00016 & 9.35 & 0 \\
\hline & MATCHED & 0.0016 & 0.00137 & 0.28 & 0.778 & MATCHED & 0.00195 & 0.00082 & 1.48 & 0.141 \\
\hline \multirow{2}{*}{ Size $_{t-1}$} & UNMATCHED & 13.23 & 13.301 & -0.49 & 0.626 & UNMATCHED & 13.23 & 11.546 & 15.01 & 0 \\
\hline & MATCHED & 13.217 & 13.186 & 0.15 & 0.877 & MATCHED & 13.2 & 13.097 & 0.55 & 0.584 \\
\hline \multirow{2}{*}{$\Delta$ (Equity to Assets Ratio) $\mathrm{t}-2$ to $\mathrm{t}-1$} & UNMATCHED & 0.00065 & 0.00089 & -0.16 & 0.871 & UNMATCHED & 0.00065 & 0.00197 & -0.54 & 0.592 \\
\hline & MATCHED & 0.0002 & -0.00058 & 0.53 & 0.598 & MATCHED & 0.00065 & 0.00083 & -0.1 & 0.921 \\
\hline \multirow{2}{*}{$\Delta($ Subordinated Debt to Assets Ratio $)$ t-2 to t-1 } & UNMATCHED & -0.00066 & -0.00013 & -2 & 0.046 & UNMATCHED & -0.00066 & $-1.30 \mathrm{E}-06$ & -5.78 & 0 \\
\hline & MATCHED & -0.00017 & -0.00021 & 0.12 & 0.904 & MATCHED & -0.00053 & $1.50 \mathrm{E}-05$ & -0.93 & 0.352 \\
\hline \multirow{2}{*}{$\Delta(\mathrm{ROA}) \mathrm{t}-2$ to $\mathrm{t}-1$} & UNMATCHED & 0.00135 & -0.00051 & 3.33 & 0.001 & UNMATCHED & 0.00135 & -0.0003 & 1.37 & 0.17 \\
\hline & MATCHED & 0.00052 & 0.00039 & 0.17 & 0.866 & MATCHED & 0.0012 & 0.00171 & -0.3 & 0.764 \\
\hline \multirow{2}{*}{$\Delta($ Size $)$ t-2 to t-1 } & UNMATCHED & -0.05719 & -0.08503 & 2.14 & 0.033 & UNMATCHED & -0.05719 & -0.06718 & 0.61 & 0.541 \\
\hline & MATCHED & -0.05713 & -0.06218 & 0.32 & 0.747 & MATCHED & -0.05725 & -0.05073 & -0.35 & 0.723 \\
\hline \multirow{2}{*}{ Relative Size $_{\mathrm{t}-1}$} & UNMATCHED & 0.3768 & 0.33171 & 0.88 & 0.379 & & & & & \\
\hline & MATCHED & 0.30894 & 0.3082 & 0.01 & 0.99 & & & & & \\
\hline \multirow{2}{*}{ Private Equity Dummy } & UNMATCHED & 0.03191 & 0.03566 & -0.18 & 0.854 & & & & & \\
\hline & MATCHED & 0.01149 & 0.02299 & -0.58 & 0.563 & & & & & \\
\hline \multirow{2}{*}{ In-State Buyer Dummy } & UNMATCHED & 0.81915 & 0.80386 & 0.35 & 0.726 & & & & & \\
\hline & MATCHED & 0.81609 & 0.82433 & -0.14 & 0.888 & & & & & \\
\hline \multirow{2}{*}{ Geographic Market Expansion } & UNMATCHED & 1.7234 & 1.6939 & 0.40 & 0.693 & & & & & \\
\hline & MATCHED & 1.7356 & 1.6529 & 0.80 & 0.425 & & & & & \\
\hline \multirow{2}{*}{ Branch Ratio } & UNMATCHED & 0.39636 & 0.3989 & -0.05 & 0.957 & & & & & \\
\hline & MATCHED & 0.39227 & 0.38041 & 0.20 & 0.842 & & & & & \\
\hline
\end{tabular}




\section{Details on Data Collection and Sample Construction}

\section{IV.A. Call Reports Data}

We use information from the FFIEC 031/041 Call Reports for all commercial banks in the US for the period 1999Q1 - 2015Q4. The call reports data are available from the Federal Reserve Bank of Chicago up to 2010Q4 and from the Central Data Repository's Public Data Distribution website from 2011Q1 onward. The FFIEC 031 report contains data for banks with domestic and foreign offices and thus includes the larger US affiliated banks, while the FFIEC 041 report contains data for banks with domestic offices only. The initial sample comprises 545,512 bank-quarter observations.

Data on the balance items for banks with domestic offices only are reported in the RCON series, and for banks with domestic and foreign offices on a consolidated basis in the RCFD series. Up to 2011Q4 the RCON and RCFD series in the call report files are identical for banks with domestic offices only, i.e., the RCFD series encompass the figures of the RCON series and differ only for banks with foreign offices. From 2012Q1 onward, the RCFD series report only the figures for banks with domestic and foreign offices and have missing observations for banks with domestic offices only. In contrast, data on the income statement items for both types of banks are reported in the RIAD series over the whole sample period.

To construct consistent balance sheet variables for the banks in our sample, we generate the total assets variable denoted $t a$, with the following STATA command:

gen $\mathrm{ta}=\mathrm{RCON} 2170$

replace ta $=$ RCFD2170 if $\mathrm{RCON} 2170 !=\mathrm{RCFD} 2170 \& \mathrm{RCFD} 2170 !=$.

Next, we drop the observations for which the variable $t a$ is missing or zero (1,515 observations), leaving 543,997 bank-quarter observations in the sample.

In Table I we define the bank-level variables used in our empirical analysis. Before applying the relevant formula for each bank variable in which an RCON series is employed, and 
similarly in order to construct the $t a$ variable above, we transform this RCON series using the following STATA command:

replace $\operatorname{rcon} Y Y=\operatorname{rcfd} Y Y$ if $\operatorname{rconYY} !=\operatorname{rcfd} Y Y \& \operatorname{rcfdY} Y !=$.

All bank-level financial characteristics reported in Table I, except from size, are trimmed after the above calculation in the $(-3,+3)$ standard deviations frame around their means.

We also collect data for a number of bank identification codes reported in the RSSD series and match them with the bank financial characteristics data set described above. ${ }^{24}$ Following this matching, we drop the bank-quarter observations for which the FDIC certificate ID number is 0 (15,728 observations) which correspond to foreign-owned institutions or branches operating in the U.S., and for which we lack data on the majority of bank financial characteristics. After this deletion, our sample includes 528,269 bank-quarter observations.

We additionally use the Institution Directory Reports for all active commercial banks available from the FDIC website to retrieve information for the primary federal regulator of each bank, the relevant FDIC field office and the FED district the bank belongs to. This information is provided on a quarterly basis from 2002Q1 onward and annually before that quarter. We match these variables with our main sample using the FDIC certificate ID. From this process another 2,843 bank-quarter observations are dropped because of missing information as to the identity of the regulator (these are mostly non-deposit Trust Companies that are not FDIC insured). We also drop 43 observations for which the primary federal regulator is OTS, leaving us with 525,384 bank-quarter observations.

\section{IV.B. Mergers and Acquisitions Data}

\footnotetext{
${ }^{24}$ From 2011Q1 onward, the vast majority of the RSSD series are not included in the quarterly files provided by the Central Data Repository's Public Data Distribution website, but are available separately on a quarterly basis from the Federal Reserve Bank of Chicago's website.
} 
The Mergers and Acquisitions (M\&As) data come from the Federal Reserve Bank of Chicago. ${ }^{25}$ These files contain all M\&As for banks and bank holding companies in the U.S. since 1976 and up to early September 2015. In our study we use only the commercial bank M\&As for the period 2000-2014.

For each M\&A deal, information for the name, city, and state of the acquirer and the target is available, along with the regulatory identifier (RSSD9001) of the two entities and the effective date of the deal. Additionally, each M\&A involving a commercial bank is classified into the following categories: charter discontinued (merger or purchase and assumption); split; sale of assets; charter retained (merger or purchase and assumption); and failure (government assistance provided). There are 6,007 M\&As between commercial banks for the 2000-2014 period. We drop the split, sale of assets, charter retained, and failure categories, as well as the cases where there is more than one acquirer for the same target at the same date. After this cleansing, we are left with 5,167 merger or purchase and assumption M\&As.

Moreover, the target's and the acquirer's top holder names and regulatory identifiers are included in the M\&A file, where present. However, we also checked the BHC membership of the acquirers and the targets involved in M\&As at the date the M\&A becomes effective using the data in the Relationships file, available online from FFIEC. This file contains data on the relationship of each financial institution with its top holder regulatory identifier (RSSD9001), along with, among others, the dates in which the relationship started, ended or changed, the percent of the equity owned by the top holder etc. We use this info, as more reliable and rich, to judge whether an M\&A deal concerns an acquirer and a target that belong in the same BHC group on the date of the M\&A, and thus there is no change in the control of the target in the M\&A deal. This type of deals where the acquirer and the target have the same top holder concern 2,265 M\&A cases, which we drop from the analysis (as in, e.g., Cornett et al, 2006; Hannan and Pilloff, 2009). After this

\footnotetext{
${ }^{25}$ The data can be found here: https://www.chicagofed.org/Home/banking/financial-institution-reports/merger-data.
} 
drop there are 2,902 M\&A cases where there is a change in control. From these, we were able to match with the call reports data 2,017 M\&A cases that are actually employed in our analysis for the period 2000-2014. ${ }^{26}$ In doing so we use the unique ID RSSD9001 identifier of each target bank, available in both the call reports data and the M\&As data, and the quarter that the deal becomes effective. In almost all cases the call report data for the target covering the quarter that the M\&A deal becomes effective is not available due to the charter discontinued characteristic of the M\&As examined. Thus, we do the matching with the quarter preceding the effective quarter of the M\&A deal.

\section{IV.C. Deal Characteristics Data}

Because the Chicago FED M\&A file does not contain any information regarding the characteristics of the M\&A deal (e.g., the deal amount, whether cash or stock is paid in the acquisition etc.), we use the SNL database. For this matching we used jointly the following set of criteria:

1. The completion date of the deal from SNL, and the date of the merge from the Chicago FED M\&A file should not differ by more than two days.

2. The name, city and state of the target and the actual acquirer reported in SNL should match with the relevant info in the Chicago FED final working M\&A sample.

\footnotetext{
${ }^{26}$ It is worth noticing that this figure of M\&A cases finally employed in the first stage of our empirical analysis is almost identical to the number of M\&As that have been approved by the FDIC and classified as "Regular M\&As" comprising 2,019 cases for the period 2000-2014, included in its relevant Annual Reports to Congress, available online at https://www.fdic.gov/bank/individual/merger/.
} 